\title{
SLAT regulates Th1 and Th2 inflammatory responses by controlling $\mathrm{Ca}^{2+} / \mathrm{NFAT}$ signaling
}

\author{
Stéphane Bécart, ${ }^{1}$ Céline Charvet, ${ }^{1}$ Ann J. Canonigo Balancio, ${ }^{1}$ Carl De Trez, ${ }^{2}$ Yoshihiko Tanaka, ${ }^{1,3}$ \\ Wei Duan, ${ }^{2}$ Carl Ware, ${ }^{2}$ Michael Croft, ${ }^{2}$ and Amnon Altman'
}

\begin{abstract}
1Division of Cell Biology and 2Division of Molecular Immunology, La Jolla Institute for Allergy and Immunology, La Jolla, California, USA. ${ }^{3}$ Division of Immunogenetics, Department of Immunobiology and Neuroscience, Medical Institute of Bioregulation, Kyushu University, Fukuoka, Japan.
\end{abstract}

\begin{abstract}
SWAP-70-like adapter of T cells (SLAT) is a novel guanine nucleotide exchange factor for Rho GTPases that is upregulated in Th2 cells, but whose physiological function is unclear. We show that SLAT ${ }^{-/-}$mice displayed a developmental defect at one of the earliest stages of thymocyte differentiation, the double-negative 1 (DN1) stage, leading to decreased peripheral $\mathrm{T}$ cell numbers. SLAT ${ }^{-/}$peripheral $\mathrm{CD}^{+} \mathrm{T}$ cells demonstrated impaired TCR/CD28-induced proliferation and IL-2 production, which was rescued by the addition of exogenous IL-2. Importantly, $\mathrm{SLAT}^{-/-}$mice were grossly impaired in their ability to mount not only $\mathrm{Th} 2$, but also Th1-mediated lung inflammatory responses, as evidenced by reduced airway neutrophilia and eosinophilia, respectively. Levels of Th1 and Th2 cytokine in the lungs were also markedly reduced, paralleling the reduction in pulmonary inflammation. This defect in mounting Th1/Th2 responses, which was also evident in vitro, was traced to a severe reduction in $\mathrm{Ca}^{2+}$ mobilization from $\mathrm{ER}$ stores, which consequently led to defective TCR/CD28-induced translocation of nuclear factor of activated T cells $1 / 2$ (NFATc1/2). Thus, SLAT is required for thymic DN1 cell expansion, $\mathrm{T}$ cell activation, and Th1 and Th2 inflammatory responses.
\end{abstract}

\section{Introduction}

Engagement of the TCR/CD3 complex by a cognate peptide bound to an appropriate MHC molecule, and of costimulatory receptors (e.g., CD28), is central to the development and function of $\mathrm{T}$ lymphocytes, a dynamic process tightly regulated by signal transduction pathways. Proper integration of these activation signals results in an optimal $\mathrm{T}$ cell response including cell proliferation and cytokine production. Moreover, $\mathrm{CD} 4^{+}$helper $\mathrm{T}$ cells can differentiate in response to antigen stimulation into 2 distinct subsets of effector cells, Th1 and Th2, based on their distinct cytokine expression profiles and their subsequent immune regulatory functions (1). Th1 cells mainly secrete IL- 2 and IFN- $\gamma$ and are essential regulators of cell-mediated immune responses against intracellular pathogens, whereas Th2 cells secrete IL-4, IL-5, and IL-10 and mediate predominantly humoral immunity and allergic responses (2). The balance between Th1 and Th2 subsets determines susceptibility to disease states: development of excess Th2 cells can lead to allergy and asthma, while an overactive Th1 response can lead to autoimmunity.

Recently, we isolated a TCR-regulated protein called SWAP-70like adapter of T cells (SLAT) (3), based on its abundant expression in Th2 cells and its homology with SWAP-70, a B cellenriched guanine nucleotide exchange factor (GEF) involved in $B$ cell activation, Ig class switching, and migration to lymphoid organs (4-6). We also found that antigen stimulation induces tyrosine phosphorylation of SLAT, association with $\zeta$ chain-

Nonstandard abbreviations used: BAL, bronchoalveolar lavage; $\left[\mathrm{Ca}^{2+}\right]_{\mathrm{i}}$, intracellular $\mathrm{Ca}^{2+}$ concentration; CD62L, CD62 ligand; DN, double-negative; DN1, doublenegative 1; DP, double-positive; GEF, guanine nucleotide exchange factor; ICCS, intracellular cytokine staining; $\mathrm{IP}_{3}$, inositol 1, 4, 5-triphosphate; $\mathrm{MMM}$, marginal metallophilic macrophage; MZM, marginal zone macrophage; NFAT, nuclear factor of activated T cells; SLAT, SWAP-70-like adapter of T cells; SOC, store-operated channel; SP, single-positive; ZAP-70, $\zeta$ chain-associated protein kinase $70 \mathrm{kDa}$.

Conflict of interest: The authors have declared that no conflict of interest exists. Citation for this article: J. Clin. Invest. 117:2164-2175 (2007). doi:10.1172/JCI31640. associated protein kinase $70 \mathrm{kDa}(\mathrm{ZAP}-70)$, and its translocation to the immunological synapse and that ectopic (retroviral) SLAT expression in CD $4^{+} \mathrm{T}$ cells moderately reduced Th 1 differentiation and enhanced Th2 development (3). The same protein, also termed IRF4-binding protein (IBP) was independently isolated by another group (7) and later found to function as a TCR-regulated GEF for the Rho GTPases Rac1 and Cdc42 (ref. 8 and C. Sedwick, unpublished observations), which are required for TCR-mediated cytoskeletal reorganization. Recently, loss of SLAT in mixed-background mice was found to lead to the spontaneous development of a lupus-like syndrome, preferentially in aged females (9).

To further investigate the role of SLAT in T cells, we generated SLAT-deficient (SLAT ${ }^{-/}$) mice on a C57BL/6 background and analyzed $\mathrm{T}$ lymphocyte development, activation, and differentiation. We demonstrate that SLAT disruption induces developmental defects at one of the earliest stages of thymocyte differentiation, the double-negative 1 (DN1) stage, resulting in altered peripheral T cell homeostasis. Moreover, $\mathrm{SLAT}^{-/-}$peripheral CD4 ${ }^{+}$ T cells displayed impaired TCR/CD28-induced proliferation and IL-2 production. Strikingly, SLAT ${ }^{-/}$mice were grossly deficient in their ability to mount Th1- and Th2-dependent lung inflammatory responses as assessed by mononuclear cell infiltration and local cytokine expression. This in vivo defect was paralleled by impaired Th1 or Th2 differentiation of SLAT $-/-\mathrm{CD}^{+}{ }^{+} \mathrm{T}$ cells in vitro. In addition, these defects were associated with a severe reduction in $\mathrm{Ca}^{2+} /$ nuclear factor of activated $\mathrm{T}$ cells $\left(\mathrm{Ca}^{2+} / \mathrm{NFAT}\right)$ signaling and a more moderate decrease in ERK1/ 2 and p38 activation. Finally, we demonstrate that the impaired Th1/Th2 responses of SLAT ${ }^{-/}$mice are a direct result of the $\mathrm{Ca}^{2+} / \mathrm{NFAT}$ signaling defect, since treatment with ionomycin fully restored the ability of $\mathrm{SLAT}^{-/-} \mathrm{CD}^{+} \mathrm{T}$ cells to differentiate into Th1 or Th2 cells. These findings demonstrate that SLAT is required for commitment of naive $\mathrm{T}$ cells to the Th1/Th2 lineages, reflecting its important role in TCR-induced $\mathrm{Ca}^{2+} / \mathrm{NFAT}$ signaling pathways. 
A

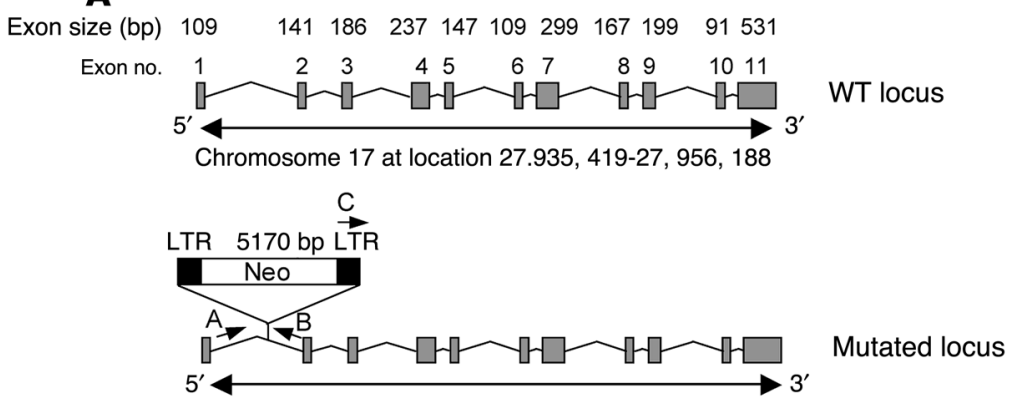

B

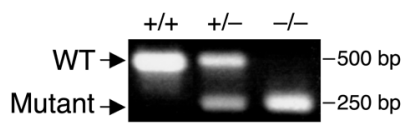

C

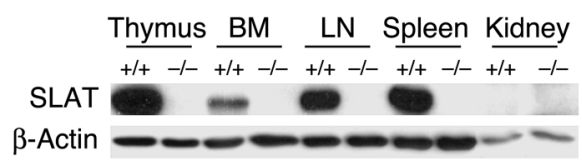

\section{Results}

Generation of SLAT $T^{-1-}$ mice. SLAT ${ }^{+/-}$heterozygous mice on a mixed $129 \times \mathrm{C} 57 \mathrm{BL} / 6$ background generated by random retroviral insertion were obtained from Lexicon Genetics Inc. (Figure 1A; see Methods). We generated homozygous $\mathrm{SLAT}^{-/-}$mice on a mixed background by crossing heterozygous parents. To obtain congenic homozygous (SLAT ${ }^{-/}$) and WT (control) mice, thus achieving a genetic uniformity, we backcrossed $\mathrm{SLAT}^{-/-}$progeny mice to C57BL/ 6 mice, selected heterozygous SLAT ${ }^{+/-}$mice, and kept backcrossing them for more than 10 generations (Figure 1B). Once this backcrossing was completed, we crossed $\mathrm{F}_{>10}$ congenic heterozygous males and females and obtained congenic homozygous $\mathrm{SLAT}^{-/}$and control $\left(\mathrm{SLAT}^{+/+}\right.$; WT) mice. SLAT ${ }^{-/-}$and control mice were born at the expected mendelian ratio, appeared healthy, and were fertile. The resulting SLAT ${ }^{-/-}$mice exhibited a complete loss of SLAT expression as revealed by Western blotting (Figure 1C).

Thymocyte development in SLAT ${ }^{-1}$ mice. Because SLAT is expressed in all lymphoid tissues except fetal liver (data not shown) (Figure $1 C$ ), and predominantly in T lymphocytes $(3,7)$, we focused our study on the consequences of SLAT inactivation in T cell physiology. SLAT ${ }^{-1-}$ mice displayed an approximately $50 \%$ reduction in thymus size and cellularity compared with the control mice (Figure 2A). $\mathrm{SLAT}^{-/-} \mathrm{CD}^{+} \mathrm{CD}^{-}, \mathrm{CD}^{-}{ }^{-} \mathrm{CD}^{+}$(single-positive [SP]), and $\mathrm{CD}^{+} \mathrm{CD}^{+}$(double-positive [DP]) thymocytes migrated normally to the proper areas in the thymus; thus, the DP thymocytes resided in the cortex, whereas the $\mathrm{CD}^{+}$and $\mathrm{CD}^{+} \mathrm{SP}$ thymocytes were concentrated in the medulla (Figure 2B). Moreover, SLAT $^{-/-}$and WT mice had similar proportions of $\mathrm{CD}^{-} \mathrm{CD}^{-}$(double-negative $[\mathrm{DN}]$ ), DP, and $\mathrm{CD}^{+}$or $\mathrm{CD}^{+} \mathrm{SP}$ thymocytes (Figure $2 \mathrm{C}$ ) and displayed similar frequencies of $\mathrm{DN}$ subsets, which differentiate sequentially through DN1 (CD25-CD44+), DN2 (CD25+CD44+), DN3 (CD25+CD44-), and DN4 (CD25-CD44-) stages (Figure 2E). However, the absolute cell number of each thymic subset (from progenitors to mature SP thymocytes) was decreased by approximately $45 \%-55 \%$ in $\mathrm{SLAT}^{-/}$- compared with WT mice (Figure 2, D and $\mathrm{F}$ ), suggesting a defect in differentiation and/or expansion of an early progenitor.

\section{Figure 1}

Targeted disruption of the SLAT locus. (A) A scheme of the SLAT locus (top) and the strategy used to disrupt the locus and screen for the WT versus mutant SLAT allele. (B) PCR genotyping using primers A, B, and C to distinguish the 500 -bp WT allele-derived A-B product from the 250-bp mutant allele-derived B-C product. (C) Tissue distribution of SLAT protein expression. Total cell lysates were prepared from thymus, BM, LNs, spleen, and kidney and probed with an anti-SLAT Ab (top) or with an actin-specific $\mathrm{Ab}$ (bottom).

Analysis of developmental stage-specific surface markers revealed that $\mathrm{SLAT}^{-/-} \mathrm{SP}$ and DP thymocytes expressed normal levels of CD69, CD62 ligand (CD62L), and TCR $\beta$ (Supplemental Figure 1; supplemental material available online with this article; doi:10.1172/JCI31640DS1), indicating normal maturation of each subset. More specifically, mature SP cells, characterized by their CD62 $\mathrm{L}^{\text {hi }} \mathrm{CD} 69^{\text {lo }} \mathrm{SP}$ phenotype, were found in the same proportion in WT and SLAT $^{-/}$mice (Supplemental Figure 1), suggesting that the thymic defect is not due to an emigration defect of mature SP thymocytes. Furthermore, WT and SLAT ${ }^{-/-}$thymocytes were similarly susceptible to cell death induced by neglect or antiFas or anti-CD3 Abs (data not shown), indicating that SLAT is not required for thymocyte survival.

Last, we assessed the effect of SLAT deficiency on thymopoiesis by injecting mice with BrdU daily for 3 or 6 days and analyzing BrdU incorporation on day 4 or 7 in each thymocyte subset. The fractions of $\mathrm{BrdU}^{+}$cells in the DN, DP, $\mathrm{CD}^{+} \mathrm{SP}$, or $\mathrm{CD}^{+} \mathrm{SP}$ subsets were not significantly different in WT and $\mathrm{SLAT}^{-/}$mice (Figure $2 \mathrm{G}$ ). However, analysis of DN subpopulations revealed that, although all DN subsets expressed similar levels of SLAT protein (Supplemental Figure 2), SLAT ${ }^{-/-}$DN1 thymocytes selectively incorporated 2-fold less BrdU after both 3 and 6 days of BrdU treatment in comparison to WT DN1 thymocytes (Figure $2 \mathrm{H}$ ). These results demonstrate that SLAT is required for optimal proliferation of DN1 thymocytes during T cell development.

Impaired $T$ cell homeostasis in SLAT $T^{-1-}$ mice. Next, we explored the peripheral lymphoid compartment in $\mathrm{SLAT}^{-/-}$mice. Histological examination did not reveal any differences in splenic architecture between WT and SLAT ${ }^{-/-}$mice (Figure 3A). Within the white pulp, $\mathrm{T}$ and $\mathrm{B}$ lymphocytes were normally segregated into discrete compartments, with $\mathrm{T}$ cells surrounded by B cell follicles. Moreover, in $\mathrm{SLAT}^{-/}$- mice, the marginal zone macrophages (MZMs) and marginal metallophilic macrophages (MMMs), present in the marginal zone (MZ) separating the red pulp from the white pulp, were properly localized to the outer and inner borders, respectively, of the MZ. These data show that SLAT is not required to maintain a normal lymphoid tissue organization. The spleen and LN cellularity in $\mathrm{SLAT}^{-/-}$mice was reduced by approximately $30 \%$ and approximately $50 \%$, respectively, compared with that in WT mice (Figure 3B). Moreover, $\mathrm{SLAT}^{-/-}$mice displayed a decrease in the frequency of $\mathrm{CD}^{+}{ }^{+} \mathrm{T}$ cells in spleen and LNs $(\sim 40 \%$ and $\sim 30 \%$ versus WT mice), whereas the frequency of $\mathrm{CD}^{+} \mathrm{T}$ cells was only slightly reduced (Figure 3C). As a result, the total numbers of $\mathrm{CD}^{+} \mathrm{T}$ cells and, to a lesser extent, of $\mathrm{CD}^{+} \mathrm{T}$ cells in peripheral lymphoid organs were reduced in $\mathrm{SLAT}^{-/-}$mice (Figure 3D). Moreover, coinjection of CFSE-labeled WT and $\mathrm{SLAT}^{-/-} \mathrm{CD}^{+}$or $\mathrm{CD}^{+}$ 

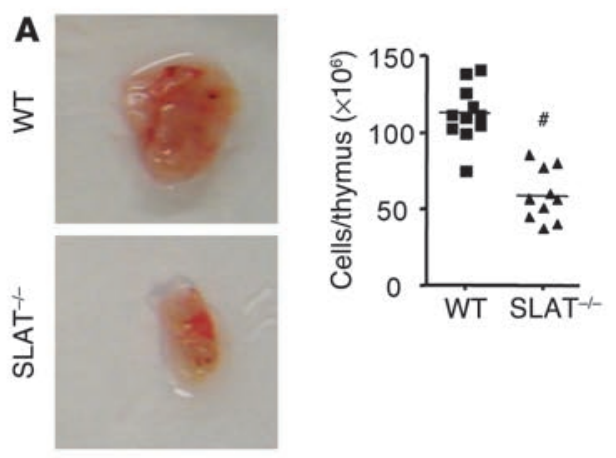

$\overline{0.5 \mathrm{~cm}}$

C
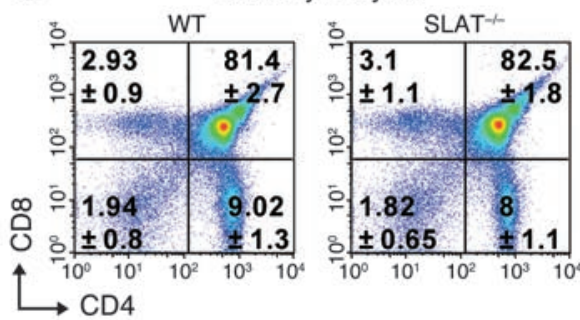

E

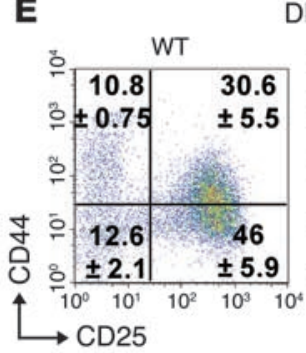

DN

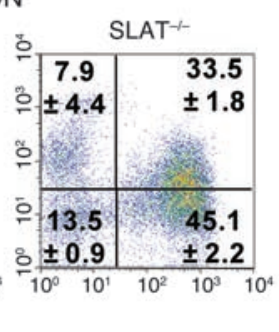

B
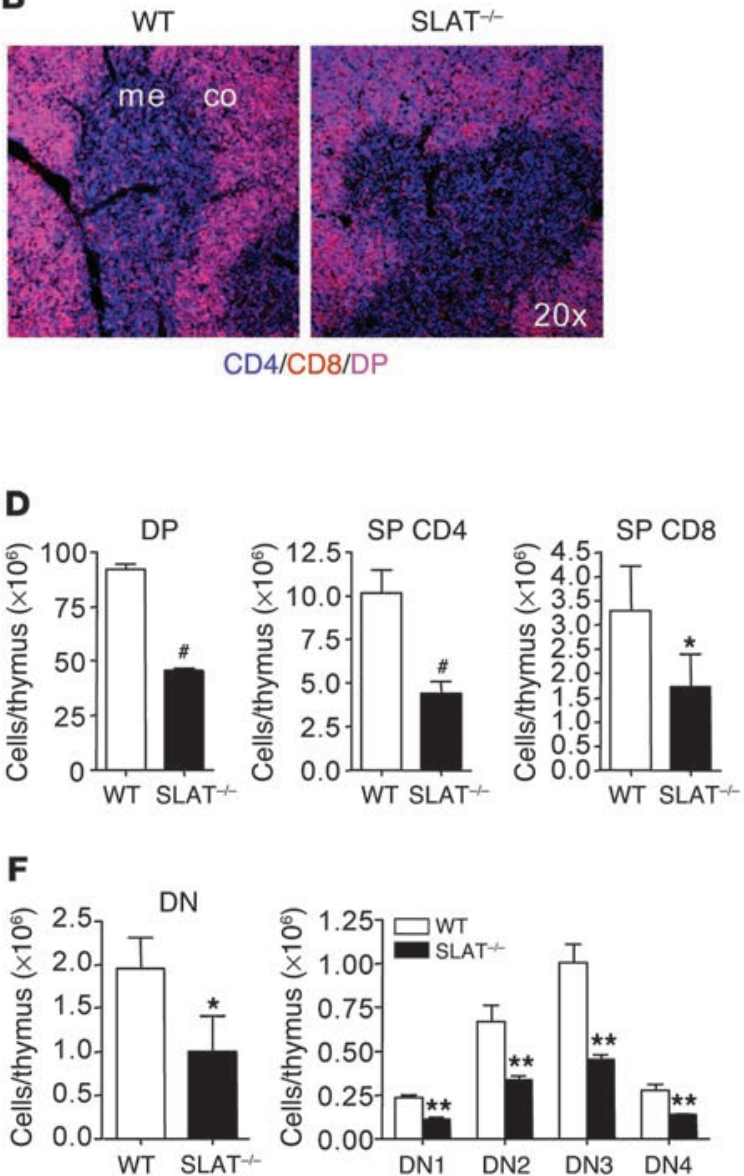

G
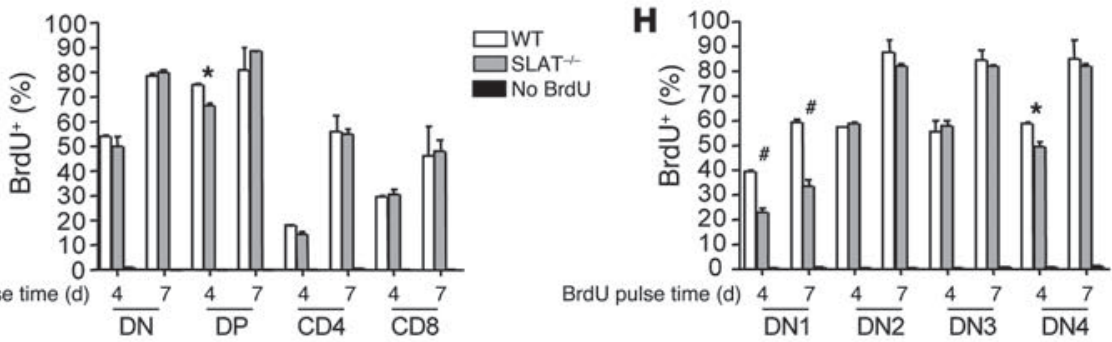

Figure 2

Thymocyte development in SLAT-/- mice. (A) Representative thymi from 8-week-old control WT or SLAT-/- mice (left); total thymocyte cell numbers from individual mice were determined (right). Lines indicate the mean, and each symbol represents an individual mouse. (B) Sections of thymi from WT (left) or SLAT ${ }^{-1-}$ (right) mice were stained with anti-CD4 (blue) and anti-CD8 (red) mAbs. Thymic medulla (me) and cortex (co) areas are indicated. (C) Total thymocytes from 8-week-old WT and SLAT ${ }^{-1-}$ mice were analyzed by flow cytometry for CD4 and CD8 expression. The percentage (mean \pm SD) of each subpopulation $(n=10)$ is shown in each quadrant. (D) Numbers of thymocyte subpopulations in WT mice and SLAT ${ }^{-1-}$ mice were calculated. (E) DN thymocytes were gated as described in Methods and analyzed for CD44 and CD25 expression. The percentage (mean \pm SD) of each subpopulation $(n=8)$ is shown. $(\mathbf{F})$ Numbers of DN thymocyte subpopulations in WT and SLAT-1- mice were calculated. (G and $\mathbf{H})$ Eight-week-old WT and SLAT ${ }^{-1-}$ mice $(n=4)$ were injected i.p. daily for 3 or 6 days with BrdU (1 mg/ml). On days 4 or 7, respectively, the percentage of $\mathrm{BrdU}^{+} \mathrm{DN}, \mathrm{DP}, \mathrm{CD} 4^{+} \mathrm{SP}$, and $\mathrm{CD} 8^{+} \mathrm{SP}(\mathrm{G})$ and the percentage of BrdU+ $\mathrm{DN}$ subpopulations in DN-gated thymocytes $(\mathbf{H})$ were analyzed. Results are expressed as mean \pm SD. Statistical differences were determined using 2-tailed Student's $t$ test. ${ }^{\star} P<0.05,{ }^{* *} P<0.01,{ }^{\#} P<0.001$, WT versus SLAT ${ }^{-1-}$ mice.

T cells did not reveal any defect in migration (as revealed on day 1 after transfer) and survival (day 7 after transfer) of SLAT ${ }^{-/-}$cells in the spleen (Supplemental Figure 3) and LNs (data not shown). Analysis of different $\mathrm{CD}^{+}$subsets did not indicate any imbalance among naive $\mathrm{CD} 44^{\text {lo }} \mathrm{CD} 62 \mathrm{~L}^{\text {hi }}$, effector $\mathrm{CD} 44^{\text {hi }} \mathrm{CD} 62 \mathrm{~L}^{\text {lo }}$, memory
$\mathrm{CD} 44{ }^{\text {hi }} \mathrm{CD} 62 \mathrm{~L}^{\mathrm{hi}}$, and $\mathrm{CD} 4{ }^{+} \mathrm{CD} 25^{+}$regulatory $\mathrm{T}$ cells in $\mathrm{SLAT}^{-/-}$ mice (Figure 3E). Together, these data show that SLAT disruption alters steady-state $\mathrm{T}$ cell homeostasis in peripheral lymphoid organs but has no impact on lymphoid organ architecture and basal activation phenotype. 

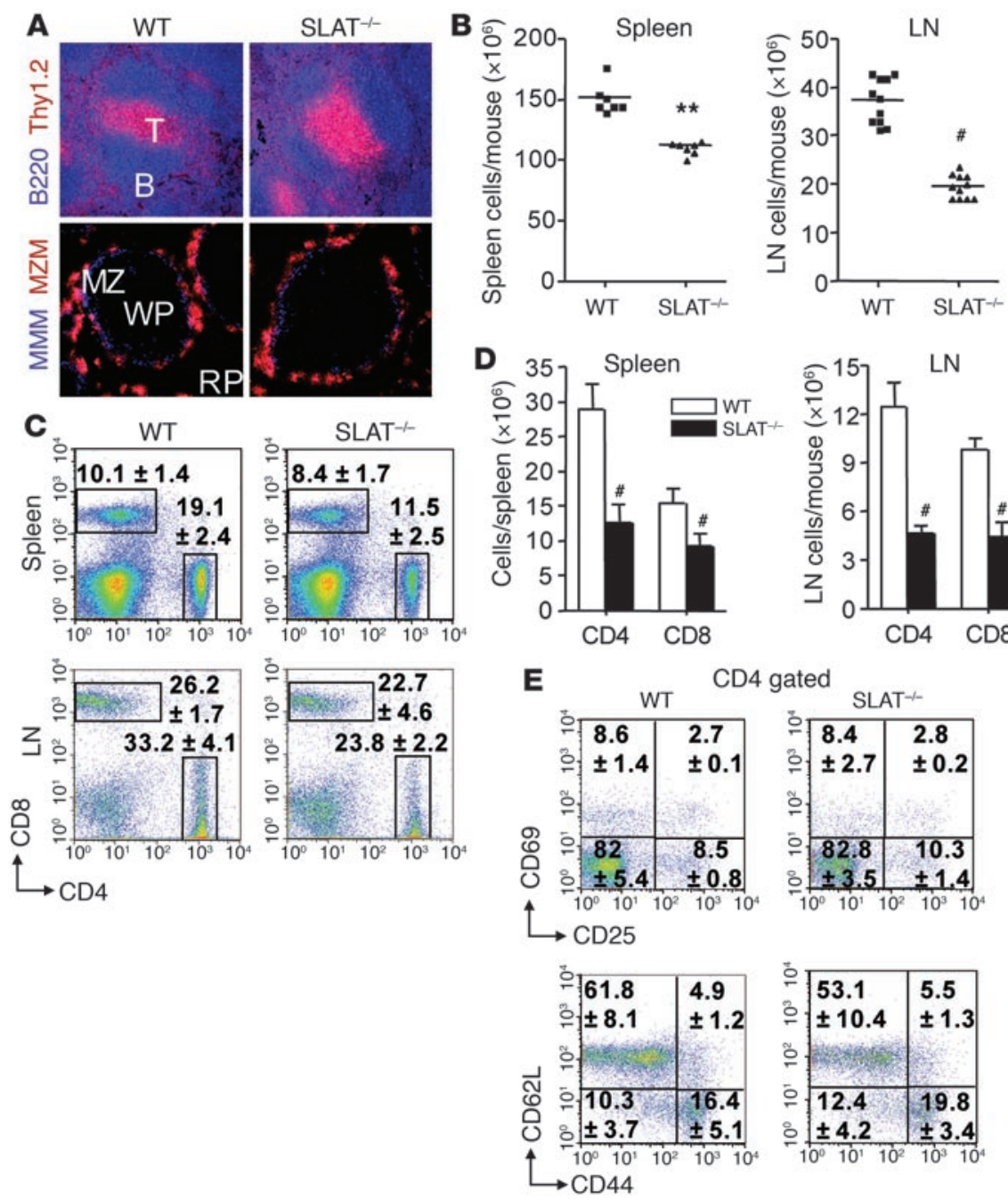

Figure 3

Phenotype of peripheral $\mathrm{T}$ cells in SLAT ${ }^{-/-}$mice. (A) Spleens were harvested for immunohistochemical analysis. Spleen section were incubated with markers specific for B (B220, blue) and T (Thy1.2, red) lymphocytes, MMM (blue), and MZM (red) (original magnification, $\times 20$ ). White pulp (WP), red pulp (RP), and marginal zone (MZ) are indicated. (B) Total cell numbers in spleens and LNs. Lines indicate the mean, and each symbol represents an individual mouse. (C) Splenocytes (upper panels) and LN cells (lower panels) from WT and SLAT ${ }^{-1}$ - mice were analyzed for CD4 and CD8 expression. The percentage (mean \pm SD) of each subpopulation $(n=10)$ is shown. (D) Total T cell numbers in spleens and LNs from WT and SLAT-/- mice. (E) CD4-gated peripheral T cells from WT and SLAT ${ }^{-/-}$mice were analyzed for CD69 and CD25 (upper panels) or CD62L and CD44 expression (lower panels). The percentage of each subpopulation $(n=6)$ is shown. Results are expressed as mean \pm SD. Statistical differences were determined as in Figure $2 .{ }^{* *} P<0.01,{ }^{\#} P<0.001$, WT versus SLAT ${ }^{-1-}$ mice.

Defective TCR-induced proliferation and IL-2 expression of SLAT $T^{-1}$ $C D 4^{+} T$ cells. Next, we examined the impact of SLAT deficiency on $\mathrm{T}$ cell activation. Proliferation of $\mathrm{SLAT}^{-/-} \mathrm{CD}^{+} \mathrm{T}$ cells in response to anti-CD3/CD28 stimulation was substantially reduced as measured by $\left[{ }^{3} \mathrm{H}\right]$ thymidine incorporation (Figure $4 \mathrm{~A}$ ). The same $\mathrm{CD}^{+}$ $T$ cells proliferated normally in response to stimulation with PMA plus ionomycin as a control (Figure 4A and Supplemental Figure 4), stimuli known to bypass TCR engagement. These results indicate that SLAT is required for proximal TCR/CD28 signaling events and rule out defects in the cell-cycle machinery itself. Analysis of CFSE-labeled CD ${ }^{+} \mathrm{T}^{-}$cells showed that $\mathrm{SLAT}^{-/-} \mathrm{CD}^{+}$

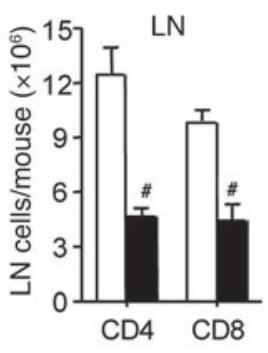

T cells divided at a slower rate (reflecting a decrease in the number of cell divisions) than WT cells in response to anti-CD3/ CD28, but not PMA/ionomycin, stimulation (Figure 4B).

Consistent with their reduced proliferation, anti-CD3/CD28-stimulated $\mathrm{SLAT}^{-/}$ $\mathrm{CD}^{+} \mathrm{T}$ cells displayed an approximately 2-fold decrease in IL-2 production (Figure $4 \mathrm{C})$. In contrast, PMA/ionomycin treatment induced a similar level of IL-2 secretion in the $2 \mathrm{CD}^{+} \mathrm{T}$ cell types (Figure 4C and Supplemental Figure 4). Addition of recombinant IL-2, however, completely restored the anti-CD3/CD28-induced proliferation (Figure 4D), indicating that signaling through the IL-2 receptor remained intact. Despite the reduction of CD3/CD28-induced proliferation and IL-2 production observed in SLAT-deficient $T$ cells, CD3/CD28 engagement induced intact upregulation of CD25 and the activation marker CD69 in $\mathrm{SLAT}^{-/-} \mathrm{CD}^{+} \mathrm{T}$ cells (Figure 4E).

SLAT $T^{-1}$ mice are resistant to Th2-driven airway inflammation. Th2 cells are responsible for the development of allergic airway inflammation $(10,11)$. We previously showed that ectopic SLAT expression has a moderate effect on Th2 development and/or activation (3). Therefore, we examined the role of SLAT in a murine model of Th2-driven allergic airway disease. WT or $\mathrm{SLAT}^{-/-}$mice were primed with OVA in alum and then challenged with aerosolized OVA. Twenty-four hours after the last OVA challenge, lung lavages were performed and the bronchoalveolar lavage (BAL) fluid assessed for inflammatory cell recruitment. Unsensitized but OVAchallenged WT (Figure 5A; WT-PBS) and SLAT $^{-/-}$(data not shown) mice were used as a negative control and did not exhibit any inflammatory response, as evidenced by the negligible number of leukocytes in the BAL fluid. However, WT mice that were OVA sensitized and challenged (Figure 5A; WT-OVA) had a dramatic increase in the total leukocyte number in the BAL fluid. The predominant infiltrate consisted of eosinophils ( $55 \%-60 \%$ of total cells), with lower numbers of macrophages $(\sim 30 \%)$ and lymphocytes $(\sim 10 \%)$ and very few neutrophils (Figure $5 \mathrm{~B})$. In striking contrast, OVA-primed SLAT ${ }^{-/}$(SLAT ${ }^{-/-}$-OVA) mice exhibited a 3.5 -fold decrease in the total number of leukocytes in the BAL fluid compared with their WT counterparts. In particular, there was a dramatic decrease in eosinophilia ( $\sim 40$-fold reduction), as well as a lower number of lymphocytes ( $~ 80 \%$ compared with WT-OVA mice), whereas the number of macrophages was not significantly affected (Figure 5B). Histological analysis revealed that WT-OVA mice developed a prominent lung inflammatory response charac- 
A

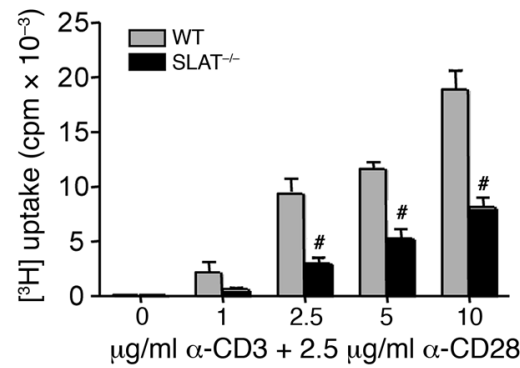

B
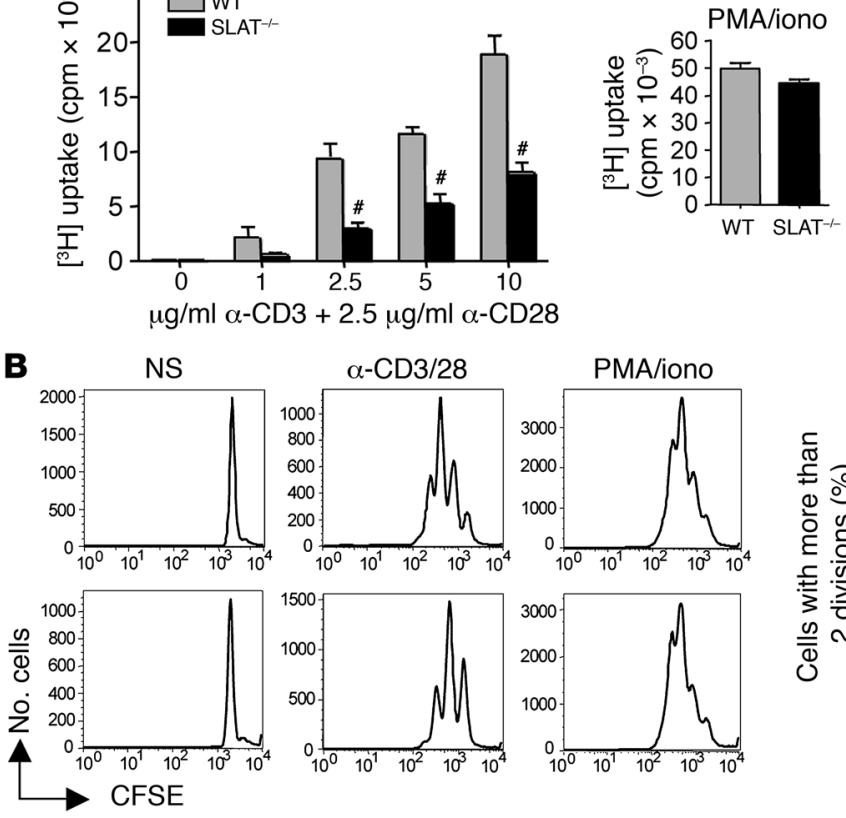

C
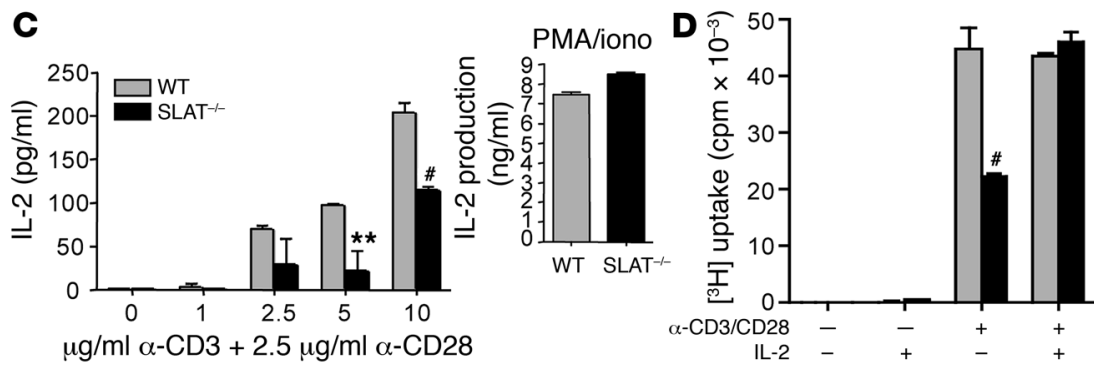

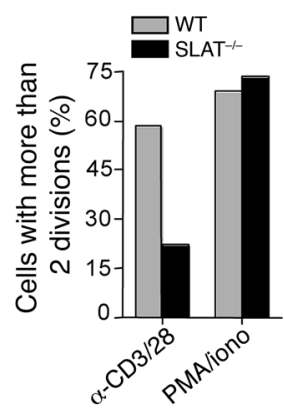

Unstimulated

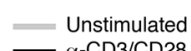

$\alpha-C D 3 / C D 28$

... PMA/iono
Figure 4

Defective activation of SLAT-/- CD4 ${ }^{+}$T cells. (A) Purified peripheral CD4+ ${ }^{+} \mathrm{T}$ cells from WT and SLAT ${ }^{-/-}$mice were stimulated with the indicated concentrations of plate-coated anti-CD3 plus soluble anti-CD28 mAbs for 48 hours. $\left[{ }^{3} \mathrm{H}\right]$ thymidine was added for the final 18 hours of culture, and proliferation was measured by tritium uptake. Proliferation of PMA (20 ng/ml) plus ionomycin-stimulated $(500 \mathrm{ng} / \mathrm{ml}) \mathrm{T}$ cells was also analyzed (right). iono, ionomycin. (B) CFSE-labeled purified $\mathrm{CD}^{+} \mathrm{T}$ cells from WT or SLAT ${ }^{-/-}$mice were left unstimulated or stimulated with anti-CD3 $(5 \mu \mathrm{g} / \mathrm{ml})$ plus anti-CD28 $(2.5 \mu \mathrm{g} / \mathrm{ml}) \mathrm{mAbs}$ or with PMA plus ionomycin for 72 hours. Cell division was determined by flow cytometry analysis (left panels). The percentage of cells with more than 2 divisions is shown (right panel). (C) Purified CD4+ T cells from WT or SLAT ${ }^{-/-}$mice were stimulated as in A, and IL-2 production was measured by an ELISA. (D) Purified CD4 ${ }^{+} \mathrm{T}$ cells from WT or SLAT $T^{-/}$mice were stimulated with anti-CD3 $(10 \mu \mathrm{g} / \mathrm{ml})$ plus anti-CD28 $(2.5 \mu \mathrm{g} / \mathrm{ml}) \mathrm{mAbs}$ or PMA plus ionomycin in the presence or absence of exogenous IL-2 (100 U/ml), and proliferation was measured as in A. (E) Purified CD4 ${ }^{+} \mathrm{T}$ cells from WT and SLAT-1- mice were stimulated as in $\mathbf{D}$ for 16 hours and analyzed by flow cytometry for CD25 or CD69 expression. Results are expressed as mean \pm SD. Statistical differences were determined as in Figure $2 .{ }^{* \star} P<0.01$, ${ }^{\#} P<0.001$, WT versus SLAT ${ }^{-1-}$ mice.
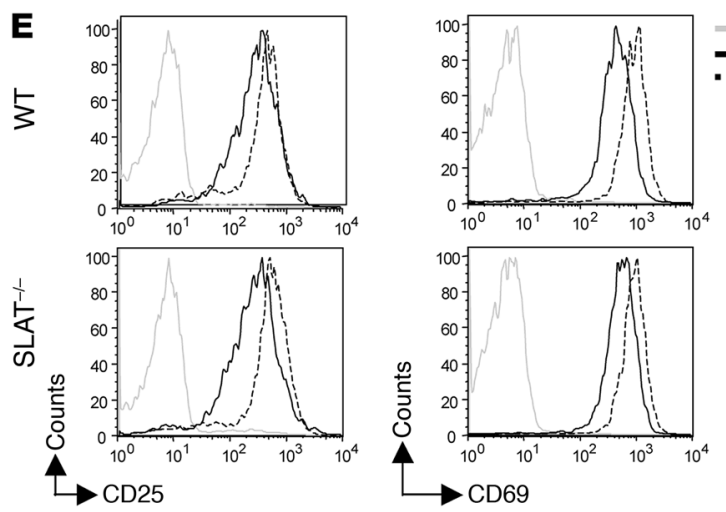

terized by perivascular and peribronchiolar infiltration of eosinophils and mononuclear cells. In contrast, $\mathrm{SLAT}^{-/-}$mice displayed a much more attenuated cell infiltration (Figure 5, C and D), as reflected by the significantly reduced inflammation score, consistent with the reduced number of cells seen in the BAL fluid from these mice. Additionally, the extensive hyperplasia of goblet cells and mucus production observed in primed WT mice was drastically reduced in $\mathrm{SLAT}^{-/-}$mice, since approximately $75 \%$ of goblet cells stained strongly with PAS in WT mice versus only approximately $15 \%-20 \%$ in SLAT ${ }^{-/-}$mice (Figure 5, E and F). Further analysis of the BAL fluid revealed a 70\%-75\% reduction in the levels of IL-4 and IL-5 in SLAT ${ }^{-/-}$-OVA mice compared with WT-OVA mice (Figure 5, $\mathrm{G}$ and $\mathrm{H}$ ). Along with this decrease, the serum level of IgE in
OVA-primed SLAT ${ }^{-/-}$mice was less than $25 \%$ of that found in WTOVA mice (Figure 5I), indicating a systemic impairment of the Th2 responses in $\mathrm{SLAT}^{-/-}$mice. Collectively, these data demonstrate that SLAT is required for the development of a Th2 response in vivo.

SLAT $T^{-1}$ mice fail to mount a Th1-induced lung inflammatory response. Since SLAT is also expressed in Th1 cells (3) (Supplemental Figure 5), we examined whether SLAT ${ }^{-/}$mice can mount a Th1-mediated inflammatory response by priming WT and $\mathrm{SLAT}^{-/-}$mice with OVA in CFA and challenging them by OVA inhalation 3 weeks later, a protocol known to induce a Th1-mediated lung inflammation (12). The total BAL fluid leukocyte number was significantly lower (2.5-fold decrease) in SLAT ${ }^{-/-}$than WT mice (Figure 6A). Th1-mediated lung inflammation involves neutrophil recruitment, in con- 

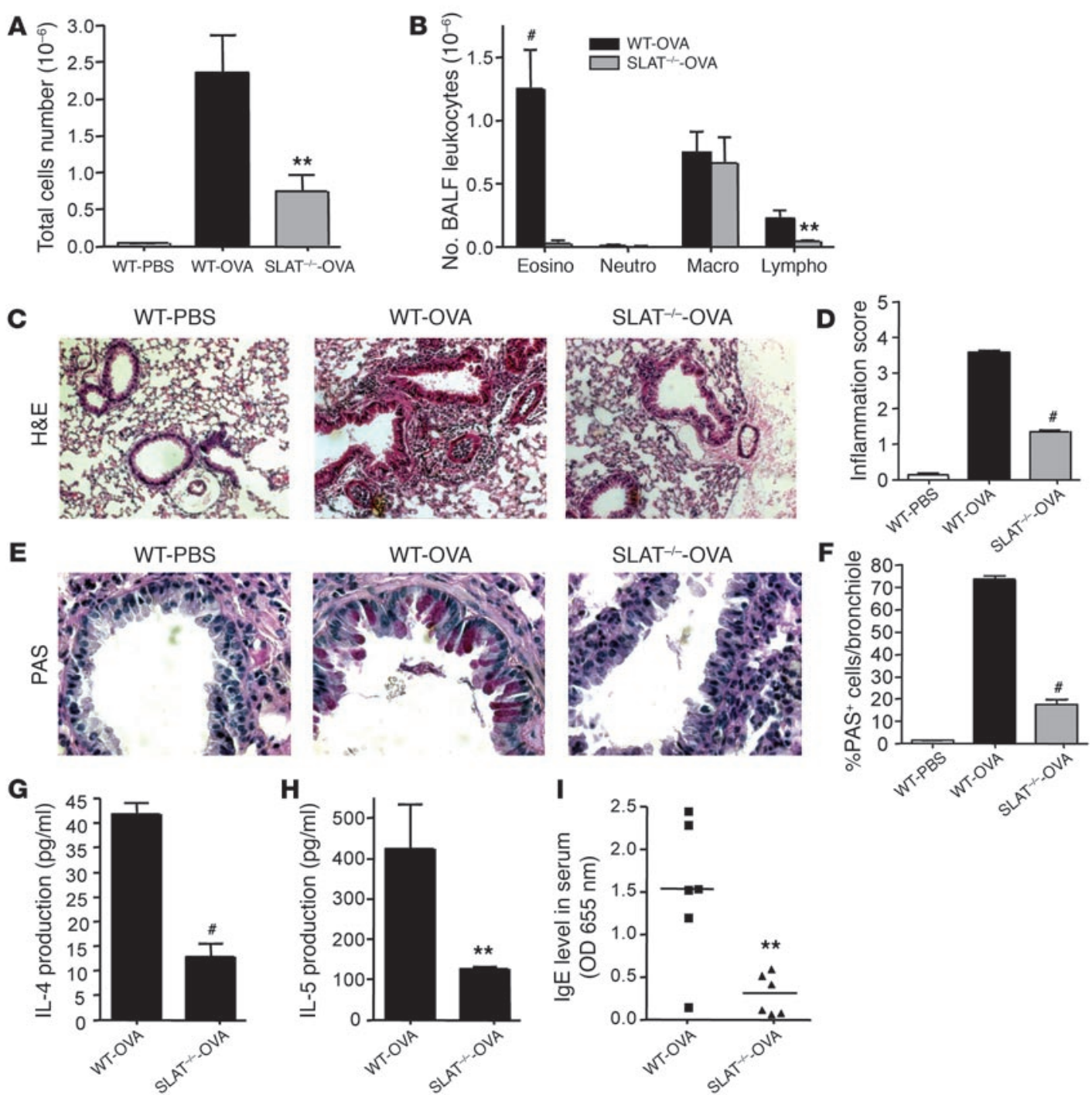

\section{Figure 5}

Impaired Th2-mediated lung inflammation in SLAT ${ }^{-/-}$mice. WT and SLAT ${ }^{-/-}$mice $(n=4$ each) were immunized i.p. with OVA in alum (WT- versus SLAT ${ }^{-1-}$-OVA mice) or injected with alum alone as a control (WT- versus SLAT ${ }^{-1-}$-PBS mice). Eighteen days later, mice were challenged by inhalation of nebulized OVA for 4 consecutive days. (A) Total cell numbers were counted in BAL fluid recovered from WT and SLAT- -1 mice 24 hours after the last OVA challenge. (B) Total numbers of eosinophils (Eosino), neutrophils (Neutro), macrophages (Macro), and lymphocytes (Lympho) were calculated from differentially stained BAL cytospins. (C) Twenty-four hours after the last OVA challenge, lung tissue sections from WT and SLAT ${ }^{-1-}$ mice were stained with H\&E (original magnification, $\times 100$ ) to visualize the inflammatory infiltrates. (D) The inflammation score of the lung sections was evaluated on an arbitrary scale from 0 to 5. (E) Lung tissue sections from WT and SLAT $T^{-/-}$mice were stained with PAS to highlight the mucus-secreting cells (original magnification, $\times 400)$. (F) The percentage of PAS ${ }^{+}$epithelial cells per bronchiole was calculated. Results are expressed as mean \pm SEM $(n=4)$. Statistical differences were determined as in Figure 2. IL-4 (G) and IL-5 (H) concentrations in BAL fluid were measured by ELISA 24 hours after the final OVA challenge. (I) Serum IgE levels were analyzed by an ELISA in individual WT (squares) or SLAT ${ }^{-1-}$ (triangles) mice. Lines indicate the mean. ${ }^{* *} P<0.01,{ }^{\#} P<0.001$, WT versus SLAT ${ }^{-1-}$ mice.

trast to a Th2-generated response, where eosinophils dominate. As expected, no eosinophils were detected in the BAL fluid from OVAprimed WT or SLAT ${ }^{-/-}$mice (Figure 6B). However, the BAL fluid from SLAT ${ }^{-/}$-OVA mice exhibited a severely reduced number of neutrophils and lymphocytes (4-5-fold and 2-fold decrease, respectively) (Figure 6B). The level of IFN- $\gamma$, a hallmark Th1 cytokine, was also reduced (3-fold decrease) in the BAL fluid of $\mathrm{SLAT}^{-1-}$ mice (Figure 6C). Analysis of H\&E-stained lung sections revealed a dense inflammatory infiltrate surrounding perivascular and peribronchiolar areas as well as a drastic hyperplasia of the bronchial epi- thelium in OVA-primed WT mice, while little or no infiltrate was detected in OVA-challenged SLAT ${ }^{-/}$mice or in control WT mice treated with PBS (Figure 6D). The severity of the inflammation was 2 -fold stronger in WT versus $\mathrm{SLAT}^{-/-}$mice based on the inflammation score (Figure 6E). These results indicate that SLAT is also required for an efficient Th1-mediated lung inflammation.

$S L A T$ is required for efficient Th1 and Th2 differentiation in vitro. To determine whether the production of Th1 and Th2 cytokines was also affected in vitro, we stimulated $\mathrm{CD}^{+} \mathrm{T}$ cells from WT and $\mathrm{SLAT}^{-/-}$mice with anti-CD3 and -CD28 mAbs, cultured them 

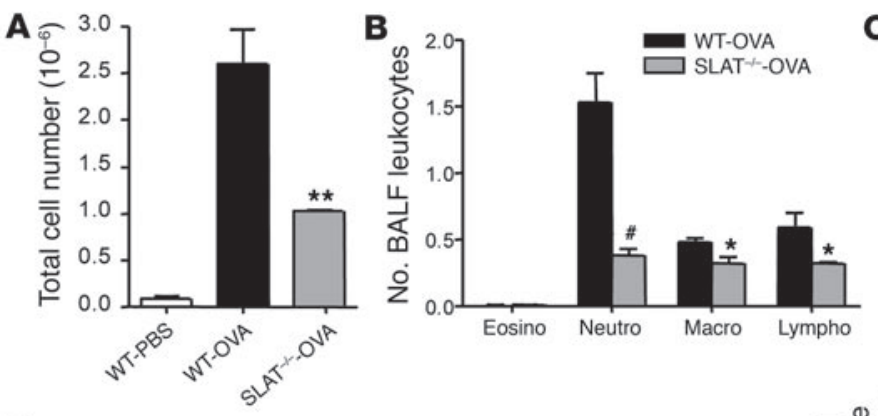

D

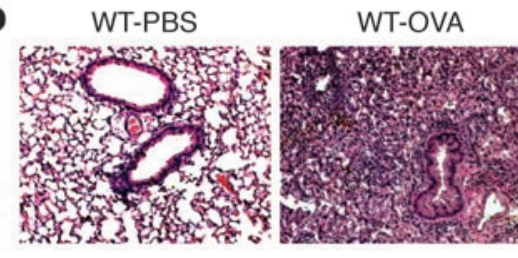

SLAT $T^{-1}-$ OVA

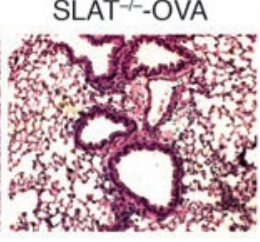

Figure 6

SLAT ${ }^{-1-}$ mice exhibit reduced Th1-mediated lung inflammation. Groups of WT and SLAT ${ }^{-/-}$mice ( $n=4$ each) were immunized s.c. with OVA in CFA (WT- versus SLAT-1--OVA mice) or injected with CFA alone (WT- versus SLAT-/--PBS mice). Mice were challenged with aerosolized OVA as in Figure 4. (A) Total cell numbers were counted in BAL recovered 24 hours after the last OVA challenge. (B) Total numbers of eosinophils, neutrophils, macrophages, and lymphocytes were calculated as in Figure 5B. BALF, BAL fluid. (C) Twenty-four hours after the final OVA challenge, IFN- $\gamma$ concentration in BAL fluid was measured by ELISA. (D) Lung tissue sections from WT and SLAT ${ }^{-/-}$mice were stained with H\&E (original magnification, $\left.\times 100\right)$. (E) Inflammation score was graded on an arbitrary scale from 0 to 5 . Results are expressed as mean $\pm \operatorname{SEM}(n=4)$. Statistical differences were determined as in Figure 2. ${ }^{\star} P<0.05,{ }^{* *} P<0.01,{ }^{\#} P<0.001$, WT versus $\mathrm{SLAT}^{-/}$mice.

under standard Th1- or Th2-polarizing conditions, and then analyzed IFN- $\gamma$ and IL-4 production, respectively, by ELISA following anti-CD3/CD28 restimulation. SLAT ${ }^{-/-} \mathrm{CD}^{+} \mathrm{T}$ cells produced less IL-4 and IFN- $\gamma$ ( $\sim 2$-fold decrease for both) than did WT cells (Figure $7, \mathrm{~A}$ and $\mathrm{B})$. This defect was also confirmed by intracellular cytokine staining (ICCS) (Figure 7C). These results are consistent with those from the in vivo models (Figures 5 and 6 ) and demonstrate that SLAT is required for efficient $\mathrm{CD} 4^{+} \mathrm{Th} 1$ and Th2 differentiation and/or expansion.

TCR signaling and role of $\mathrm{Ca}^{2+}$ and NFAT in SLAT-mediated Th1/Th2 differentiation. In order to gain more insight into the activation defects of SLAT ${ }^{-/}$T cells, we analyzed several TCR-induced signaling events. The TCR/ CD28-induced phosphorylation of $\zeta$ chain-associated protein kinase $70 \mathrm{kDa}$ (ZAP-70), linker for activa-

\section{Figure 7}

SLAT is required for Th1 and Th2 development in vitro. (A-C) Naive WT or SLAT ${ }^{-1-}$ CD4 ${ }^{+}$T cells were stimulated with anti-CD3/CD28 mAbs and differentiated in vitro under Th1- or Th2-inducing conditions. Levels of IL-4 (A) and IFN- $\gamma(\mathbf{B})$ in culture supernatants were quantified by ELISA 24 hours after restimulation (restim.) with anti-CD3 plus anti-CD28 mAbs. (C) Cytokine-secreting cells were analyzed by ICCS 8 hours after restimulation. Results are expressed as mean \pm SD. Statistical differences were determined as in Figure 2. ${ }^{\star *} P<0.01,{ }^{\#} P<0.001$, WT versus $\mathrm{SLAT}^{-/}$mice.
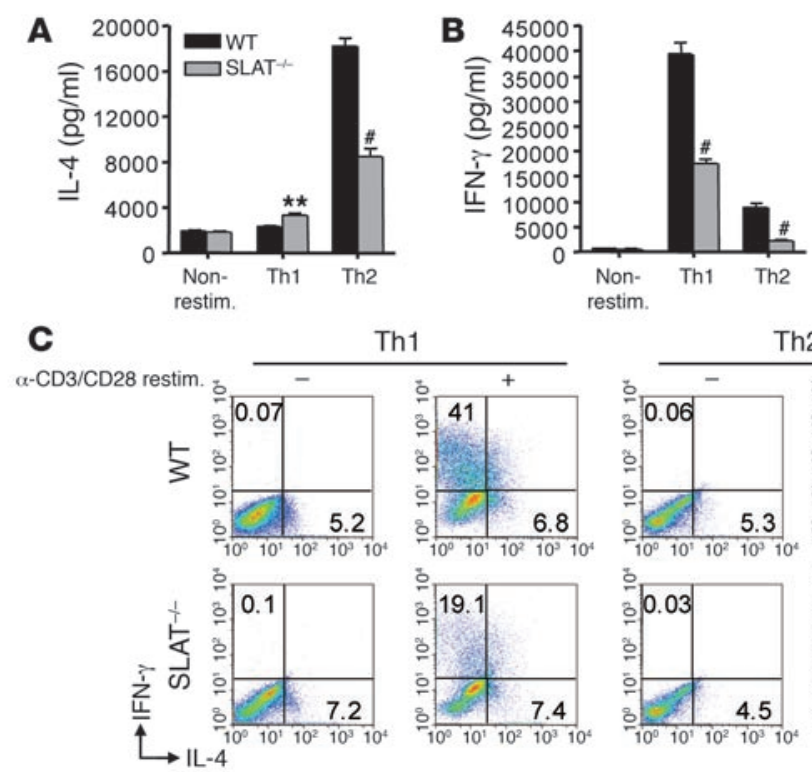

Th1
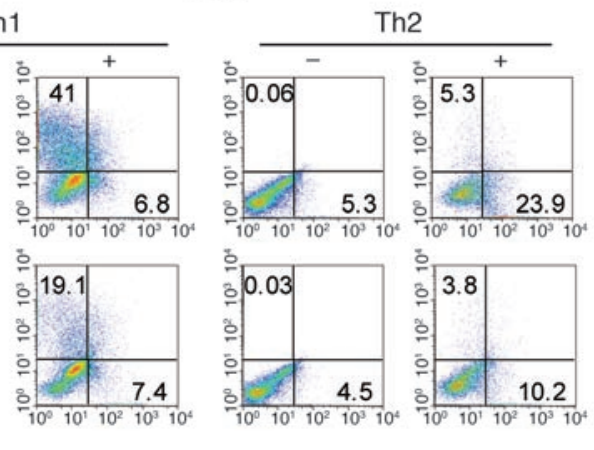
A

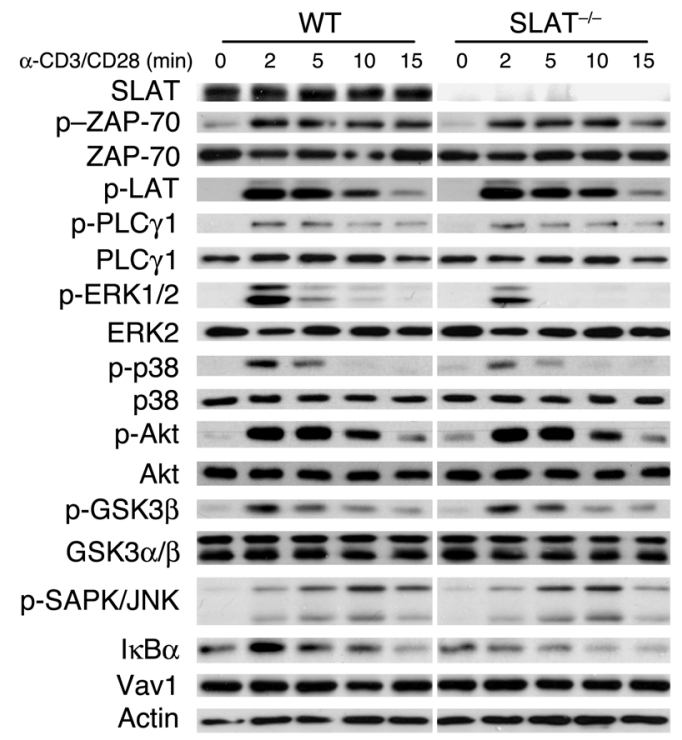

B-CD3/CD28
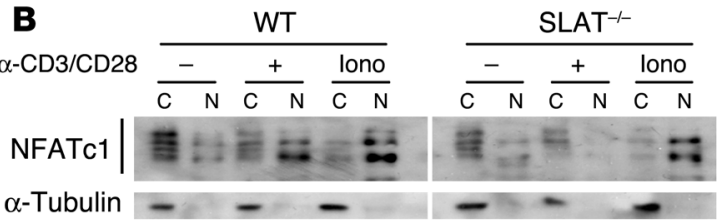

Lamin B $\rightarrow-\infty+\cdots+-$

SLAT

$\alpha-\mathrm{CD} 3 / \mathrm{CD} 28$
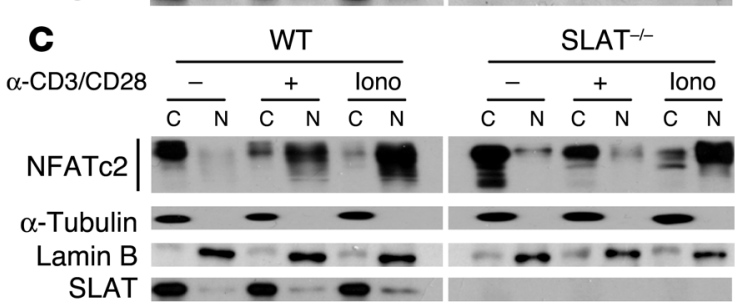

D

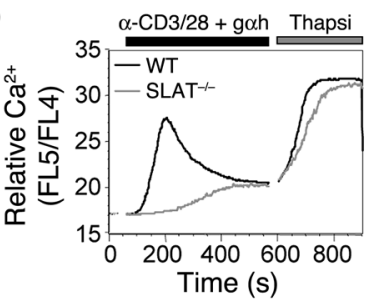

E

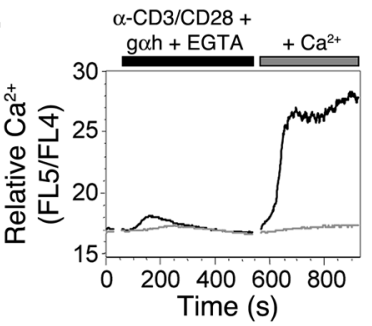

$\mathbf{F}$

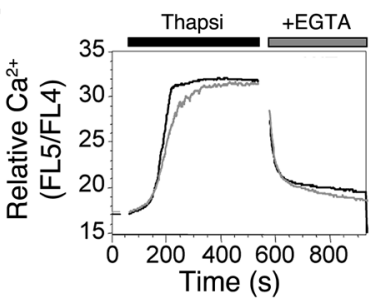

G

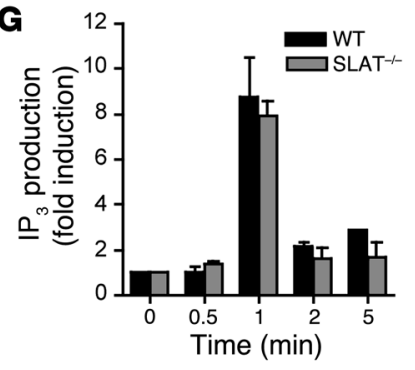

Figure 8

Impaired TCR/CD28-induced signaling events in SLAT ${ }^{-/-}$mice. (A) WT and SLAT ${ }^{-/-}$ total $T$ cells were stimulated with crosslinked anti-CD3 plus anti-CD28 $(20 \mu \mathrm{g} / \mathrm{ml}$ each) $m A$ bs for the indicated times. Cell lysates were separated by SDS-PAGE and immunoblotted with the indicated Abs. SAPK, stress-activated protein kinase. (B and C) WT and SLAT ${ }^{-\prime-}$ T cells were stimulated with anti-CD3 $(10 \mu \mathrm{g} / \mathrm{ml})$ plus anti-CD28 $(2.5 \mu \mathrm{g} / \mathrm{ml}) \mathrm{mAbs}$ and recombinant IL-2 (100 U/ml) for 48 hours, rested overnight, and restimulated with antiCD3/CD28 mAbs or ionomycin (lono) for 2 hours. Cytoplasmic (C) and nuclear (N) fractions were purified and immunoblotted with anti-NFATc1 Ab (B) or anti-NFATc2 $\mathrm{Ab}(\mathbf{C})$. Fractions were also immunoblotted with an anti-SLAT Ab, or with anti-tubulin and anti-lamin $B$ Abs to confirm purity of the cytoplasmic and nuclear fractions, respectively. (D-F) Defective $\mathrm{Ca}^{2+}$ signaling in SLAT-I- T cells. Changes in $\left[\mathrm{Ca}^{2+}\right]_{\mathrm{i}}$ were analyzed by flow cytometry in indo-1loaded T cells from WT and SLAT ${ }^{-1-}$ mice. TCR/CD28 costimulation was performed using a crosslinking goat antihamster (goh) Ig Ab in the absence (D) or presence $(E)$ of $1 \mathrm{mM}$ EGTA, followed by the addition of $1 \mu \mathrm{M}$ thapsigargin (Thapsi) (D) or $2 \mathrm{mM} \mathrm{CaCl}_{2}(\mathbf{E})$. (F) $\left[\mathrm{Ca}^{2+}\right]_{i}$ changes in response to thapsigargin, followed by EGTA treatment. Data are expressed as a histogram displaying FL5/FL4 ratio versus time (s). (G) A graph showing mean levels of $\mathrm{IP}_{3}( \pm \mathrm{SD})$ generated in primary WT or SLAT ${ }^{-1-} \mathrm{T}$ cells after CD3/CD28 crosslinking for the indicated times. ( $H$ and I) WT and $\mathrm{SLAT}^{-/-} \mathrm{CD}^{+} \mathrm{T}$ cells were stimulated under neutral conditions with anti-CD3 $(1 \mu \mathrm{g} / \mathrm{ml})$ plus anti-CD28 $(2.5 \mu \mathrm{g} / \mathrm{ml})$ in the presence or absence of the indicated ionomycin concentrations for 6 days (1st stim.). After 24 hours of restimulation with anti-CD3/CD28 Abs with or without ionomycin, production of IL-4 (H) or IFN- $\gamma(\mathbf{I})$ was measured by ELISA. Results are expressed as mean \pm SD. Statistical differences were determined as in Figure 2. $\# P<0.001$, WT versus SLAT ${ }^{-l-}$ mice.
$\left(\left[\mathrm{Ca}^{2+}\right]_{\mathrm{i}}\right)$, in particular the early phase, most likely reflecting $\mathrm{Ca}^{2+}$ release from ER stores (15), was severely reduced in the absence of SLAT (Figure 8D). However, thapsigargin (Figure 8D) or ionomycin (data not shown) stimulation triggered a similar $\left[\mathrm{Ca}^{2+}\right]_{i}$ increase in both WT and SLAT ${ }^{-1-} \mathrm{T}$ cells, indicating that the ER $\mathrm{Ca}^{2+}$ pool as well as the dye loading were very similar in the 2 cell types. To gain further information about the nature of the $\mathrm{Ca}^{2+}$ defect and the relative contribution of $\mathrm{Ca}^{2+}$ release from intracellular stores versus $\mathrm{Ca}^{2+}$ influx, we used EGTA to chelate extracellular calcium and abrogate calcium influx. In the absence of extracellular calcium, TCR/CD28 crosslinking induced a transient and weak eleva- tion in $\left[\mathrm{Ca}^{2+}\right]_{\mathrm{i}}$ (representing $\mathrm{Ca}^{2+}$ release from intracellular stores) in WT, but not mutant, T cells (Figure 8E). When the medium was subsequently supplemented with $2 \mathrm{mM} \mathrm{Ca}^{2+}$, the WT T cells, but not the mutant cells, displayed a large increase in $\left[\mathrm{Ca}^{2+}\right]_{\mathrm{i}}(\mathrm{Fig}-$ ure $8 \mathrm{E})$. This increase reflects $\mathrm{Ca}^{2+}$ influx through plasma membrane store-operated channels (SOCs), which is triggered by $\mathrm{Ca}^{2+}$ release from ER stores. As a control, treatment with thapsigargin, a specific inhibitor of the sarcoplasmic/ER $\mathrm{Ca}^{2+}$-ATPase (SERCA) pump, which triggers $\mathrm{Ca}^{2+}$ influx by depleting intracellular $\mathrm{Ca}^{2+}$ stores independently of receptor stimulation, induced a similar $\mathrm{Ca}^{2+}$ influx in both WT and mutant T cells (Figure 8F). This result 
indicates that the depletion of intracellular $\mathrm{Ca}^{2+}$ stores is capable of activating plasma membrane SOCs in an intact manner in SLAT $^{-/-}$T cells. In addition, the production of the second messenger mediating $\mathrm{Ca}^{2+}$ release from intracellular stores in response to TCR/CD28 costimulation, i.e., inositol 1, 4, 5-triphosphate ( $\left.\mathrm{IP}_{3}\right)$, was similar in WT and SLAT ${ }^{-1-}$ T cells (Figure 8G). This result is consistent with the normal activation of PLC $\gamma 1$ in both cell types (Figure 8A). Together, these results indicate that SLAT is required for $\mathrm{Ca}^{2+}$ release from intracellular stores and consequently for $\mathrm{Ca}^{2+}$ influx, by acting downstream of $\mathrm{IP}_{3}$ production.

The above findings suggested a causal link between the impaired Th1/Th2 responses and the defect in $\mathrm{Ca}^{2+} / \mathrm{NFAT}$ signaling in SLAT $^{-/-} \mathrm{T}$ cells. To further address this potential link, we stimulated CD4 ${ }^{+} \mathrm{T}$ cells from $\mathrm{WT}$ and $\mathrm{SLAT}^{-/-}$mice with anti-CD3/CD28 $\mathrm{mAbs}$ in the presence or absence of different doses of ionomycin, and production of IL-4 and IFN- $\gamma$ was measured 24 hours after restimulation. Addition of ionomycin to the primary differentiation cultures rescued IL- 4 and IFN- $\gamma$ production in SLAT ${ }^{-/-}$T cells in a dose-dependent manner (Figure 8, H and I), independent of the presence of ionomycin during the restimulation step. Furthermore, addition of ionomycin only during the restimulation phase did not rescue the IL-4 and IFN- $\gamma$ defects (Figure 8, H and I). Taken together, these results strongly suggest that SLAT is required for TCR-induced $\mathrm{Ca}^{2+} / \mathrm{NFAT}$ signaling and, therefore, for proper Th1/ Th2 development and effector functions.

\section{Discussion}

In this study, we examine the role of SLAT in T cell physiology through the analysis of SLAT-deficient mice. We report that SLAT deficiency induces a partial blockade in thymopoiesis at the DN1 stage, resulting in a decrease in the peripheral $\mathrm{T}$ cell pool. In addition to its role in thymic development, SLAT is important for optimal $\mathrm{T}$ cell activation in terms of TCR/CD28-mediated proliferation and IL-2 production. This reduced activation results from a severely impaired $\mathrm{Ca}^{2+}$ mobilization and NFATc1/2 nuclear translocation and a more moderate decrease in ERK1/2 and p38 activation. Moreover, we provide evidence that SLAT contributes to the development of Th1 and Th2 responses in vitro and in vivo. Last, our finding that ionomycin rescues Th1/Th2 differentiation in $\mathrm{SLAT}^{-/-}$mice strongly suggests that the defective $\mathrm{Ca}^{2+} / \mathrm{NFAT}$ signaling is the cause of impaired Th1/Th2 responses in these mice.

Developing $\mathrm{T}$ cells in the thymus receive differentiation and expansion signals from distinct classes of surface receptors such as cytokine receptors or the pre-TCR, triggering a broad spectrum of signaling pathways (16). We found that the altered thymopoiesis in $\mathrm{SLAT}^{-/-}$mice was due to a specific defect in expansion of the DN1 population, which contains the earliest intrathymic progenitors, resulting in reduced cellularity in the thymus and, consequently, in the peripheral $\mathrm{T}$ cell compartment. The differentiation and proliferation of DN subpopulations are mainly governed by complex interrelationships among Notch, c-kit, and IL-7R signaling pathways $(17,18)$, raising a question about the role of SLAT in this signaling network, apart from its TCR-dependent function in the periphery. While Notch1 signaling in DN thymocytes promotes VDJ $\beta$ rearrangement and is involved in eliminating thymocytes that fail to form functional pre-TCRs (19), c-kit and IL-7R signaling pathways are predominantly involved in the proliferation of DN thymocytes $(20,21)$. Specifically, c-kit/stem cell factor (c-kit/SCF) interactions have been shown to be involved in the earliest stages of thymopoiesis by promoting the proliferation of these immature thymocytes (20), a role reminiscent of the SLATmediated function revealed by our current findings. In contrast, IL-7 is involved in the expansion and survival of more mature thymocytes from the DN2 stage and beyond $(22,23)$. It is thus tempting to speculate that SLAT may regulate c-kit signaling in the very immature thymocyte compartment.

In the periphery, we observed a mild $\mathrm{T}$ cell lymphopenia in both spleen and LNs from SLAT ${ }^{-/}$- mice, likely occurring as a direct consequence of the decreased thymic output. This peripheral $\mathrm{T}$ cell defect might be related to the spontaneous lupus-like syndrome associated with the accumulation of effector/memory $\mathrm{T}$ cells, recently reported in aged $\mathrm{SLAT}^{-/-}$mice on a mixed background (9). Indeed, several studies showed that lymphopenia can predispose mice to several autoimmune diseases such as IDDM, SLE, colitis, or RA $(24,25)$. The compensatory homeostatic proliferation, normally a consequence of such lymphopenia, has been reported to drive the development of autoimmunity via the rapid expansion of autoreactive short-lived memory-like $T$ cells within the depleted niche $(26,27)$. It would thus be interesting to assess whether our $\mathrm{SLAT}^{-/-}$mice, which are on a homogenous C57BL/ 6 background, in contrast to the previously studied mixed-background SLAT ${ }^{-/-}$ mice (9), are also more susceptible to a lupus-like syndrome or other autoimmune manifestations.

We also showed that SLAT ${ }^{-/-}$peripheral $\mathrm{CD}^{+} \mathrm{T}$ cells fail to fully proliferate and produce IL-2 in response to TCR/CD28 costimulation. However, PMA plus ionomycin treatment bypassed this defect, demonstrating that SLAT is part of a signaling pathway downstream of the TCR but upstream of PKC and/or calcium signaling, which is necessary for full $\mathrm{T}$ cell activation. In support of this notion, we previously showed that SLAT interacts with ZAP-70 (3), and others have shown that SLAT is phosphorylated by Lck, a prerequisite for stimulation of its GEF activity toward Rho GTPases (8), which thereby implicates SLAT as a regulator of proximal TCR signaling events. Our findings that the TCR-induced CD25 upregulation on $\mathrm{SLAT}^{-/-} \mathrm{CD}^{+} \mathrm{T}$ cells was normal, and that the proliferative defect could be overcome by adding exogenous IL-2, indicate that this defect is due to altered TCR signaling and not IL-2 receptor signaling. Although the NFAT pathway was severely impaired in SLAT ${ }^{-/}$T cells, the proliferative response and IL-2 production were not as drastically affected, consistent with findings that NFATc1 and NFATc2 are not critical for proliferation and/or IL-2 production by naive T cells $(28,29)$.

Given the abundant expression of SLAT in Th2 cells (3), we analyzed the susceptibility of SLAT ${ }^{-/-}$mice to Th2-mediated airway inflammation. We clearly show here that $\mathrm{SLAT}^{-/-}$mice are resistant to development of this Th2-mediated inflammatory disease. SLAT was also required for the production of Th2 cytokines, i.e., IL-4 and IL-5, both in vivo and in vitro, establishing its important role in Th2-mediated responses. Our findings differ from those of a recent study, which reported intact production of Th2 cytokines in SLAT-deficient mice (9). The reason for this discrepancy is unknown but may reflect our use of $\mathrm{SLAT}^{-/-}$mice on a C57BL/6 background, in contrast to the mixed C57BL/ $6 \times 129$ background mice used by Fanzo et al. We previously reported that SLAT overexpression in Jurkat T cells activated an IL4 reporter gene and that retroviral SLAT transduction of primary $\mathrm{T}$ cells moderately reduced the proportion of Th1 cells and, conversely, increased the level of IL-4-producing cells (3). However, our current in vivo and in vitro findings, obtained in the biologically more relevant context of SLAT-deficient mice, clearly indicate that SLAT is required 
for optimal development and effector functions of both Th1 and Th 2 cells. The requirement of SLAT for optimal Th 1 development is consistent with the IFN- $\gamma$ defect displayed by SLAT ${ }^{-/-}$T cells on a mixed background (9).

Several transcription factors including c-Maf, GATA-3, T-bet, and NFAT were reported to play major roles in the Th1/Th2 balance (30). Interestingly, the nuclear translocation of both NFATc1 and NFATc2 was strongly reduced in the absence of SLAT. Furthermore, the addition of ionomycin could (a) restore a proper nuclear translocation of NFAT and (b) rescue decreased production of both IL-4 and IFN- $\gamma$ in SLAT ${ }^{-/}$T cells. Analysis of NFAT-deficient mice revealed that NFATc1 deficiency results in an impaired Th2 response by decreasing IL-4 production (31), whereas NFATc2 deficiency enhances Th2 development by prolonging IL-4 transcription $(29,32)$. Interestingly, mice lacking both NFAT isoforms have a profound defect in the production of both Th1 and Th2 cytokines (13), consistent with our findings. Moreover, transgenic mice expressing a dominant-negative form of NFAT were shown to be resistant to allergic pulmonary inflammation (33). Hence, the impaired activation of both NFATc1 and NFATc 2 accounted for the defect in Th1/Th2 polarization, rendering SLAT ${ }^{-/-}$mice resistant to lung inflammation. Therefore, SLAT regulates early TCR signaling and controls lung inflammation by promoting nuclear localization of both NFATc1 and NFATc2 induced by early TCR/ CD28 instructive signals.

Analysis of TCR/CD28-induced early signaling events indicated intact activation of ZAP-70, LAT, and PLC $\gamma 1$ in SLAT ${ }^{-/-} \mathrm{CD}^{+}$ $\mathrm{T}$ cells and an apparently intact NF- $\mathrm{KB}$ activation. Rather, the signaling defect appeared to be restricted to the $\mathrm{Ca}^{2+} / \mathrm{NFAT}$ pathway, consistent with our findings that overexpression of WT SLAT in Jurkat T cells activated an NFAT, but not NF- $\mathrm{KB}$ or activator protein 1 (AP-1), reporter gene (unpublished observations). The defective TCR/CD28-induced NFATc1/2 nuclear translocation, which we observed in $\mathrm{SLAT}^{-/-} \mathrm{T}$ cells, resulted from a severe defect in $\mathrm{Ca}^{2+}$ mobilization. The ability of thapsigargin and ionomycin, either as an initial stimulus or following TCR/CD28 crosslinking, to stimulate an intact $\mathrm{Ca}^{2+}$ response in $\mathrm{SLAT}^{-1-} \mathrm{T}$ cells indicates that these cells express release-competent intracellular $\mathrm{Ca}^{2+}$ stores as well as functional plasma membrane SOCs. On the other hand, the failure of TCR/CD28 crosslinking and subsequent $\mathrm{Ca}^{2+}$ addition to induce a significant increase in $\left[\mathrm{Ca}^{2+}\right]_{\mathrm{i}}$ in $\mathrm{SLAT}^{-/} \mathrm{T}$ cells when extracellular $\mathrm{Ca}^{2+}$ was chelated strongly suggests that the primary $\mathrm{Ca}^{2+}$ defect in $\mathrm{SLAT}^{-/-} \mathrm{T}$ cells resides in the receptor-induced release of $\mathrm{Ca}^{2+}$ from intracellular stores, which is stimulated by the binding of the second messenger $\mathrm{IP}_{3}$ to its receptor on the ER and, in turn, is required for subsequent $\mathrm{Ca}^{2+}$ influx.

The generation of $\mathrm{IP}_{3}$ from phosphatidylinositol bisphosphate $\left(\mathrm{PIP}_{2}\right)$ is mediated by TCR-activated PLC $\gamma 1$. However, we did not observe any defect in TCR-induced PLC $\gamma 1$ phosphorylation (and, hence, activation) or in $\mathrm{IP}_{3}$ generation in $\mathrm{SLAT}^{-/-} \mathrm{T}$ cells. Therefore, our findings indicate that SLAT acts downstream of PLC $\gamma 1$ dependent $\mathrm{IP}_{3}$ production to regulate $\mathrm{Ca}^{2+}$ release from the ER. Additional work will be required to elucidate the role of SLAT in controlling $\left[\mathrm{Ca}^{2+}\right]_{\mathrm{i}}$, but it is tempting to speculate that SLAT could regulate $\mathrm{ER} \mathrm{Ca}^{2+}$ channels or sensors, e.g., the $\mathrm{IP}_{3}$ receptor (15) or stromal interaction molecule 1 (STIM1) $(34,35)$, or interact with other cytosolic proteins to allow efficient $\mathrm{Ca}^{2+}$ release (36).

In summary, our findings establish an important role of SLAT in $\mathrm{T}$ cell function. We provide strong evidence that SLAT plays a major role in the commitment of naive $\mathrm{CD}^{+} \mathrm{T}$ cells to both the
Th1 and Th2 lineages, reflecting its important role in regulating proximal TCR signaling events, specifically the $\mathrm{Ca}^{2+} / \mathrm{NFAT}$ pathway. Therefore, SLAT is a hitherto unrecognized component of the machinery that regulates $\mathrm{Ca}^{2+}$ signaling pathways in $\mathrm{T}$ cells and perhaps other hematopoietic cells. Ongoing studies in our laboratory are aimed at elucidating in more detail the mechanism through which SLAT regulates early $\mathrm{Ca}^{2+}$ signaling events and, subsequently, Th1/Th2 lineage commitment. This analysis may reveal new mechanisms that regulate Th differentiation and effector functions and, therefore, improve our understanding of Th1- and Th2-driven diseases such as autoimmunity and asthma and their treatments.

\section{Methods}

Generation of SLAT ${ }^{-/-}$mice. SLAT ${ }^{+/-}$mice on a mixed $129 \times \mathrm{C} 57 \mathrm{BL} / 6$ background were obtained from Lexicon Genetics Inc. The mice were derived by random genomic insertion of a retroviral cassette into ES (129SvEv) cells. The mutation affected an intronic sequence between exons 1 and 2 of the SLAT gene (Figure 1A). Analysis of genomic DNA using a probe specific for the retroviral targeting cassette confirmed a single mutation event. Targeted ES cells were injected into C57BL/ 6 blastocysts to generate chimeric mice, which were backcrossed to C57BL/6 mice to obtain heterozygous $\mathrm{SLAT}^{+/-}$mice on a mixed $129 \times \mathrm{C} 57 \mathrm{BL} / 6$ background. These $\mathrm{SLAT}^{+/-}$mice were intercrossed to obtain homozygous null mice (SLAT ${ }^{-/}$) mice and then backcrossed to C57BL/6 mice for more than 10 generations. Finally, $\mathrm{F}_{>10}$ congenic heterozygous males and females were crossed to obtain congenic SLAT ${ }^{-/-}$and WT control mice. Mice were genotyped by PCR on genomic DNA using the SLAT-intronic oligonucleotide primers A (5' -TTCTCTTGAAGAAGACCTGACTGAG-3') and B (5'-TAGACATCTTCATGGAGTTCAGGA-3'), which flank the retroviral insertion, plus primer C (5'-AAATGGCGTTACTTAAGCTAGCTTGC-3') corresponding to an LTR sequence of the retroviral cassette, in order to distinguish the mutated versus the endogenous SLAT allele. Age- and sex-matched 6- to 12-week-old WT or SLAT-/- C57BL/6 mice were used in all experiments and were kept under specific pathogen-free conditions in accordance with the $\mathrm{NIH}$ guidelines for the care and use of laboratory animals. Animal studies were approved by the Institutional Animal Care and Use Committee of the La Jolla Institute for Allergy and Immunology.

Flow cytometry. Thymus, spleen, or LN cell suspensions were prepared, counted, and labeled with the following fluorochrome-conjugated Abs (BD Biosciences): anti-CD4 (FITC or CyChrome), anti-CD8 (APC or CyChrome), anti-CD25 (APC), anti-CD44 (FITC or PE), anti-CD69 (PE), anti-CD62L (FITC), anti-TCR $\beta$ (FITC), anti-Mac-1 (CyChrome), and anti-Gr-1 (CyChrome). Acquisition was performed on a FACSCalibur flow cytometer (BD) and analyzed with FlowJo software (version 8.4.5; Tree Star). DN thymocyte subsets were analyzed for expression of CD44 (PE) and CD25 (APC) after all cells stained by a cocktail of CyChromeconjugated anti-CD4, -CD8, -Mac-1, and -Gr-1 Abs were gated out. For intracellular BrdU staining, a FITC-BrdU Flow Kit and FITC-conjugated anti-BrdU Ab (BD Biosciences) were used.

Cell purification, culture, and stimulation. After red blood cell lysis, murine LN and spleen T cells were enriched to greater than $90 \%$ purity on mouse $\mathrm{T}$ cell enrichment columns ( $\mathrm{R} \& \mathrm{D}$ Systems). CD4 ${ }^{+} \mathrm{T}$ cells were isolated by positive selection using anti-CD4 (L3T4) mAb-coated microbeads (MACS). T cells were cultured in RPMI-1640 medium (Life Technologies) supplemented with $10 \%$ FBS, $2 \mathrm{mM}$ glutamine, $1 \mathrm{mM}$ sodium pyruvate, $10 \mathrm{mM}$ HEPES, $1 \mathrm{mM}$ MEM nonessential amino acid solution, and $100 \mathrm{U} / \mathrm{ml}$ each of penicillin $\mathrm{G}$ and streptomycin (Life Technologies).

For short stimulation (signaling experiments), $3 \times 10^{6}$ to $5 \times 10^{6} \mathrm{~T}$ cells resuspended in serum-free medium were incubated for 30 minutes on ice 
with $20 \mu \mathrm{g} / \mathrm{ml}$ each anti-mouse $\mathrm{CD} 3 \varepsilon \mathrm{mAb}$ (145-2C11; Biolegend) and anti-CD28 mAb (37.51; Biolegend), followed by crosslinking with goat anti-hamster $\operatorname{IgG}$ (Pierce) for the indicated times at $37^{\circ} \mathrm{C}$ with gentle shaking. For long stimulation (proliferation, CFSE dilution, and Th1/Th2 differentiation), purified total $\mathrm{T}$ cells or $\mathrm{CD} 4^{+} \mathrm{T}$ cells were stimulated with plate-coated anti-CD3 plus soluble anti-CD28 mAbs or with PMA plus ionomycin as indicated. In some experiments, the cells were stimulated in the presence of $100 \mathrm{U} / \mathrm{ml}$ recombinant human IL-2 (PeproTech) or cultured under standard Th1- or Th2-polarizing conditions (3).

$T$ cell proliferation and CFSE analysis. Purified T cells $\left(2 \times 10^{5}\right.$ cells $\left./ 150 \mu \mathrm{l}\right)$ were seeded in 96-well flat-bottom tissue culture plates with the indicated concentrations of plate-coated anti-CD3 plus soluble anti-CD28 $(2.5 \mu \mathrm{g} /$ $\mathrm{ml}) \mathrm{mAbs}$ or with PMA $(20 \mathrm{ng} / \mathrm{ml})$ plus ionomycin $(0.5 \mu \mathrm{g} / \mathrm{ml})$. Where indicated, recombinant human IL-2 $(100 \mathrm{U} / \mathrm{ml})$ was added. After 48 hours, cells were pulsed with $1 \mu \mathrm{Ci}$ of $\left[{ }^{3} \mathrm{H}\right]$ thymidine for an additional 16 hours and then harvested for scintillation counting. All assays were conducted in triplicate. Cell division was analyzed by prelabeling T cells with $1 \mu \mathrm{M}$ CFSE (Molecular Probes; Invitrogen) and stimulating them at a concentration of $1.5 \times 10^{6} / \mathrm{ml}$ with plate-coated anti-CD3 and soluble anti-CD28 mAbs $(2.5$ $\mu \mathrm{g} / \mathrm{ml}$ each) for 72 hours. CFSE intensity was measured by flow cytometry.

Western blotting. Cell lysis, SDS-PAGE separation, transfer to nitrocellulose membranes, and development of blots using an ECL system (Amersham Biosciences) were performed as described previously (3). Membranes were probed with the following Abs; SLAT-specific antisera were prepared as previously described (3). Anti-ZAP-70 (99F2), -phospho-Tyr319 ZAP-70, -phospho-Tyr191 LAT, -phospho-Tyr783 PLC $\gamma 1$, -phospho-Thr202/ Tyr204 ERK1/2, -phospho-Tyr185 JNK, -phospho-Thr180/182 p38, -p38, -phospho-Ser9 GSK3 $\beta$, -Akt, -IKB $\alpha$ polyclonal Abs and -phosphoSer473 Akt rabbit mAbs were obtained from Cell Signaling Technology. Rat anti- $\alpha$-tubulin (YL1/2) Ab was purchased from Serotec, anti-actin $\mathrm{mAb}$ was from Stratagene, and anti-Vav1 and -GSK3 $\alpha / \beta$ rabbit mAbs were purchased from Upstate. Anti-NFATc1 (7A6), anti-NFATc2 (4G6-G5), antiERK2 mAbs, and polyclonal anti-lamin B Ab were purchased from Santa Cruz Biotechnology Inc. Signals were quantified by densitometry using NIH ImageJ software (http://rsb.info.nih.gov/ij/).

Subcellular fractionation. Cytoplasmic and nuclear fractionation was prepared from primary T cells as described previously (37). Briefly, $2 \times 10^{6}$ to $3 \times 10^{6}$ cells/condition were washed with ice-cold PBS, lysed in hypotonic buffer A (10 mM HEPES, pH 7.9, 10 mM KCl, 0.1 mM EDTA, 1 mM DTT, and protease inhibitors) and centrifuged for 2 minutes $\left(14,000 \mathrm{~g}\right.$ at $\left.4^{\circ} \mathrm{C}\right)$. The supernatant was collected as the cytosolic fraction. Nuclear pellets were washed twice with hypotonic buffer, resuspended for 30 minutes at $4^{\circ} \mathrm{C}$ in $40 \mu \mathrm{l}$ of buffer B (20 mM HEPES, pH 7.9, $400 \mathrm{mM} \mathrm{NaCl}, 1 \mathrm{mM}$ EDTA, $1 \mathrm{mM}$ DTT, and proteases inhibitors) and centrifuged for $10 \mathrm{~min}$ utes at $14,000 \mathrm{~g}$, and the supernatant was collected as the nuclear fraction. Equal amounts of proteins from the cytosolic and nuclear fractions were separated on a $6 \%$ SDS-PAGE gel, transferred to nitrocellulose membranes, and immunoblotted with the indicated Abs.

Immunohistochemistry. Immunohistochemistry of spleen and thymus specimens was performed as previously described (38). The following Abs were used: 30-H12 (anti-CD90.2), RA3-6B2 (anti-CD45R/B220), L3T4 (anti-CD4), 53-6.7 (anti-CD8 $\alpha$ ), and streptavidin-AP (all from BD Biosciences - Pharmingen); MOMA-1 (anti-MMM) and ERTR-9 (anti-MZM) (from BMA Biomedicals); and streptavidin-Cy3 (Zymed Laboratories). Digitized images were acquired using a confocal imaging station (BioRad MRC-1024 confocal microscope) with a krypton/argon ion laser and Nikon TE 300 inverted microscope and processed with Photoshop software (version 7.0; Adobe).

$B r d U$ administration and detection. Mice were treated daily for 3 or 6 days with $1 \mathrm{mg}$ BrdU (BD Biosciences) dissolved in PBS by i.p. injection. Twenty- four hours after the last injection, mice were killed, and thymocyte, spleen, or $\mathrm{LN}$ cell suspensions were prepared. BrdU incorporation was detected by intracellular staining using the BD Biosciences - Pharmingen BrdU Flow Kit according to the manufacturer's instructions. T cells from mice not treated with BrdU were stained as controls.

OVA-induced airway inflammation. Mice were either sensitized by i.p. injection of $20 \mu \mathrm{g}$ of OVA protein (Grade V; Sigma-Aldrich) adsorbed to $2 \mathrm{mg}$ of aluminum hydroxide (alum) gel (Imject Alum; Pierce) in PBS on days 0 and 14 to induce a Th2 response or sensitized by s.c. injection of $50 \mu \mathrm{g}$ OVA in CFA (Difco; BD Diagnostics) to promote a Th1 response (12). Nonsensitized, control mice received $2 \mathrm{mg}$ of alum in PBS or CFA alone. On day 18, mice received aerosolized OVA $(5 \mathrm{mg} / \mathrm{ml}$ in $20 \mathrm{ml}$ of PBS) for 30 minutes, once a day for 4 consecutive days, by ultrasonic nebulization. Mice were sacrificed 18-24 hours after the last aerosol challenge and assessed for lung inflammation. Collection of BAL fluid and determination of cytokine levels, differential counts of mononuclear cells, and histological analysis were carried out as previously described (12).

In vitro Th1/Th2 differentiation. Th1/Th2 differentiation cultures were prepared as previously described (12). On day 6, cells were collected and washed, and an equal number of viable cells were restimulated with plate-bound anti-CD3/CD28 mAbs $(1 \mu \mathrm{g} / \mathrm{ml}$ each) without any additional cytokines. ICCS for IL- 4 and IFN- $\gamma$ was performed after 10 hours of restimulation in the presence of GolgiStop (BD Biosciences) for the last 8 hours of culture. In parallel, supernatants were collected after 24 hours of restimulation, and the production of IL- 4 and IFN- $\gamma$ was measured by a standard ELISA. For ionomycin-mediated rescue experiments, ionomycin was added at the initiation of the primary culture and/or restimulation culture

ELISA. ELISAs were performed on culture supernatants or BAL fluids with purified anti-IL-2, anti-IL-4, or anti-IFN- $\gamma(2 \mu \mathrm{g} / \mathrm{ml}$; BD Biosciences - Pharmingen) as capture Abs, the corresponding biotinylated Abs $(1 \mu \mathrm{g} / \mathrm{ml})$, HRP-conjugated streptavidin (Amersham Biosciences), and tetramethylbenzidine peroxidase EIA substrate (Bio-Rad) according to the recommended protocol. Recombinant mouse IL-2, IL-4, and IFN- $\gamma$ (BD Biosciences - Pharmingen) were used as standards. Total serum IgE levels were quantified by ELISA using capture and biotinylated $\mathrm{mAbs}$ from CALTAG Laboratories.

ICCS. Analysis of cytokine-producing cells by ICCS was performed as described previously (12).

Intracellular calcium measurement. Purified $\mathrm{T}$ cells were loaded with indo-1 ( $2 \mu \mathrm{g} / \mathrm{ml}$; Molecular Probes; Invitrogen) in cell-loading medium (HBSS supplemented with $1 \mathrm{mM} \mathrm{CaCl}_{2}, 1 \mathrm{mM} \mathrm{MgCl}_{2}$, and $0.5 \% \mathrm{BSA}$ ) in the presence of $4 \mathrm{mM}$ probenecid for 45 minutes at $37^{\circ} \mathrm{C}$ in the dark. Dye-loaded cells were washed twice with cell loading medium and were incubated with anti-CD3 $(10 \mu \mathrm{g} / \mathrm{ml})$ and anti-CD28 $(2.5 \mu \mathrm{g} / \mathrm{ml}) \mathrm{mAbs}$ for 30 minutes at room temperature. Unbound Abs were removed by centrifugation, and cells were then resuspended in cell-loading medium to determine a baseline level of $\mathrm{Ca}^{2+}$. Goat anti-hamster $\mathrm{Ab}(10 \mu \mathrm{g} / \mathrm{ml})$ was then added to crosslink surface receptors with or without $1 \mathrm{mM}$ EGTA (to chelate extracellular $\mathrm{Ca}^{2+}$ ), and the solution was then incubated with $1 \mu \mathrm{M}$ thapsigargin, $2 \mathrm{mM} \mathrm{CaCl}_{2}$, or $1 \mathrm{mM} \mathrm{EGTA}$, as indicated. Cells were analyzed by reading the emission at $500 \mathrm{~nm}$ (FL4 channel) and 460 $\mathrm{nm}$ (FL5 channel) at different time points on an LSRII instrument (BD) and calculating the FL5/FL4 emission ratio.

$I P_{3}$ production. Cells $\left(4 \times 10^{6}\right)$ were stimulated with crosslinked anti-CD3 plus anti-CD28 mAbs for the indicated times. Stimulation was terminated by adding ice-cold TCA followed by 15 minutes incubation on ice. The samples were centrifuged at $1400 \mathrm{~g}$ at $4^{\circ} \mathrm{C}$ for 15 minutes. The supernatants were extracted with 10 volumes of water-saturated diethyl ether and neutralized with $1 \mathrm{M} \mathrm{NaHCO}_{3}$. $\mathrm{IP}_{3}$ was quantitated in duplicate samples 
using a competitive $\left[{ }^{3} \mathrm{H}\right] \mathrm{IP}_{3}$ binding assay (Amersham) according to the manufacturer's protocol.

Statistics. Statistical significance was analyzed by 2 -tailed Student's $t$ test. Unless otherwise indicated, data represent the mean $\pm \mathrm{SD}$, with $P<0.05$ considered statistically significant.

\section{Acknowledgments}

We thank all the members of the Cell Biology Division of the La Jolla Institute for Allergy and Immunology for helpful comments, Svetlana Lebedeva for initiating animal breeding and genotyping, Leo Fernandez and Kassandra Cooper for assistance with flow cytometry, and K. Sugie for technical advice. This work was supported by NIH grants AI68320 (to A. Altman), AI33068 (to C. Ware), and AI70535 (to M. Croft) and fellowships from the Fondation pour la Recherche Médicale (to S. Bécart) and the Philippe
Foundation (to S. Bécart and C. Charvet). This is manuscript number 790 from La Jolla Institute for Allergy and Immunology.

Received for publication January 29, 2007, and accepted in revised form May 9, 2007.

Address correspondence to: Amnon Altman, Division of Cell Biology, La Jolla Institute for Allergy and Immunology, 9420 Athena Circle, La Jolla, California 92037, USA. Phone: (858) 752-6808; Fax: (858) 752-6986; E-mail: amnon@liai.org.

Céline Charvet's present address is: Institute for Molecular Medicine and Cell Research, Freiburg, Germany.

Stéphane Bécart and Céline Charvet contributed equally to this work.
1. Mosmann, T.R., and Coffman, R.L. 1989. TH1 and TH2 cells: different patterns of lymphokine secretion lead to different functional properties. Annu. Rev. Immunol. 7:145-173.

2. Murphy, K.M. 1998. T lymphocyte differentiation in the periphery. Curr. Opin. Immunol. 10:226-232.

3. Tanaka, Y., et al. 2003. SWAP-70-like adapter of T cells, an adapter protein that regulates early TCRinitiated signaling in Th2 lineage cells. Immunity. 18:403-414.

4. Borggrefe, T., Wabl, M., Akhmedov, A.T., and Jessberger, R. 1998. A B-cell-specific DNA recombination complex. J. Biol. Chem. 273:17025-17035.

5. Shinohara, M., et al. 2002. SWAP-70 is a guaninenucleotide-exchange factor that mediates signalling of membrane ruffling. Nature. 416:759-763.

6. Pearce, G., et al. 2006. Signaling protein SWAP-70 is required for efficient $\mathrm{B}$ cell homing to lymphoid organs. Nat. Immunol. 7:827-834.

7. Gupta, S., et al. 2003. Molecular cloning of IBP a SWAP-70 homologous GEF, which is highly expressed in the immune system. Hum. Immunol. 64:389-401.

8. Gupta, S., et al. 2003. T cell receptor engagement leads to the recruitment of IBP, a novel guanine nucleotide exchange factor, to the immunological synapse. J. Biol. Chem. 278:43541-43549.

9. Fanzo, J.C., et al. 2006. Loss of IRF-4-binding protein leads to the spontaneous development of systemic autoimmunity. J. Clin. Invest. 116:703-714. doi:10.1172/JCI24096.

10. Elias, J.A., et al. 2003. New insights into the pathogenesis of asthma. J. Clin. Invest. 111:291-297. doi:10.1172/JCI200317748.

11. Herrick, C.A., and Bottomly, K. 2003. To respond or not to respond: T cells in allergic asthma. Nat. Rev. Immunol. 3:405-412.

12. Salek-Ardakani, S., So, T., Halteman, B.S., Altman, A., and Croft, M. 2004. Differential regulation of Th2 and Th1 lung inflammatory responses by protein kinase C $\theta$. J. Immunol. 173:6440-6447.

13. Peng, S.L., Gerth, A.J., Ranger, A.M., and Glimcher, L.H. 2001. NFATc1 and NFATc2 together control both $\mathrm{T}$ and $\mathrm{B}$ cell activation and differentiation.

\section{Immunity. 14:13-20.}

14. Ansel, K.M., Lee, D.U., and Rao, A. 2003. An epigenetic view of helper T cell differentiation. Nat. Immunol. 4:616-623.

15. Lewis, R.S. 2001. Calcium signaling mechanisms in T lymphocytes. Annu. Rev. Immunol. 19:497-521.

16. Kuo, C.T., and Leiden, J.M. 1999. Transcriptional regulation of T lymphocyte development and function. Annu. Rev. Immunol. 17:149-187.

17. Robey, E.A., and Bluestone, J.A. 2004. Notch signaling in lymphocyte development and function. Curr. Opin. Immunol. 16:360-366.

18. Di Santo, J.P., and Rodewald, H.R. 1998. In vivo roles of receptor tyrosine kinases and cytokine receptors in early thymocyte development. Curr. Opin. Immunol. 10:196-207.

19. Wolfer, A., Wilson, A., Nemir, M., MacDonald, H.R., and Radtke, F. 2002. Inactivation of Notch1 impairs VDJ $\beta$ rearrangement and allows pre-TCRindependent survival of early $\alpha \beta$ lineage thymocytes. Immunity. 16:869-879.

20. Rodewald, H.R., Kretzschmar, K., Swat, W., and Takeda, S. 1995. Intrathymically expressed c-kit ligand (stem cell factor) is a major factor driving expansion of very immature thymocytes in vivo. Immunity. 3:313-319.

21. von Freeden-Jeffry, U., Solvason, N., Howard, M., and Murray, R. 1997. The earliest T lineage-committed cells depend on IL-7 for Bcl-2 expression and normal cell cycle progression. Immunity. 7:147-154.

22. Peschon, J.J., et al. 1994. Early lymphocyte expansion is severely impaired in interleukin 7 receptordeficient mice. J. Exp. Med. 180:1955-1960.

23. Morrissey, P.J., et al. 1994. Steel factor (c-kit ligand) stimulates the in vitro growth of immature $\mathrm{CD}^{-} /$ CD4-/CD8- thymocytes: synergy with IL-7. Cell. Immunol. 157:118-131.

24. Gleeson, P.A., Toh, B.H., and van Driel, I.R. 1996 Organ-specific autoimmunity induced by lymphopenia. Immunol. Rev. 149:97-125.

25. Koh, W.P., et al. 1999. TCR-mediated involvement of $\mathrm{CD}^{+}$transgenic $\mathrm{T}$ cells in spontaneous inflammatory bowel disease in lymphopenic mice. J. Immunol. 162:7208-7216.
26. King, C., Ilic, A., Koelsch, K., and Sarvetnick, N. 2004. Homeostatic expansion of T cells during immune insufficiency generates autoimmunity. Cell. 117:265-277.

27. Baccala, R., and Theofilopoulos, A.N. 2005. The new paradigm of T-cell homeostatic proliferationinduced autoimmunity. Trends Immunol. 26:5-8.

28. Yoshida, H., et al. 1998. The transcription factor NF-ATc1 regulates lymphocyte proliferation and Th2 cytokine production. Immunity. 8:115-124.

29. Xanthoudakis, S., et al. 1996. An enhanced immune response in mice lacking the transcription factor NFAT1. Science. 272:892-895.

30. Mowen, K.A., and Glimcher, L.H. 2004. Signaling pathways in Th2 development. Immunol. Rev. 202:203-222.

31. Ranger, A.M., et al. 1998. Delayed lymphoid repopulation with defects in IL-4-driven responses produced by inactivation of NF-ATc. Immunity. 8:125-134.

32. Hodge, M.R., et al. 1996. Hyperproliferation and dysregulation of IL-4 expression in NF-ATp-deficient mice. Immunity. 4:397-405.

33. Diehl, S., et al. 2004. Inhibition of NFAT specifically in T cells prevents allergic pulmonary inflammation. J. Immunol. 172:3597-3603.

34. Zhang, S.L., et al. 2005. STIM1 is a $\mathrm{Ca}^{2+}$ sensor that activates CRAC channels and migrates from the $\mathrm{Ca}^{2+}$ store to the plasma membrane. Nature. 437:902-905.

35. Spassova, M.A., et al. 2006. STIM1 has a plasma membrane role in the activation of store-operated $\mathrm{Ca}^{2+}$ channels. Proc. Natl. Acad. Sci. U. S. A. 103:4040-4045.

36. Gallo, E.M., Cante-Barrett, K., and Crabtree, G.R. 2006. Lymphocyte calcium signaling from membrane to nucleus. Nat. Immunol. 7:25-32.

37. Charvet, C., et al. 2006. Vav1 promotes T cell cycle progression by linking TCR/CD28 costimulation to FOXO1 and $\mathrm{p}^{27^{\mathrm{kip} 1}}$ expression. J. Immunol. 177:5024-5031.

38. Benedict, C.A., et al. 2006. Specific remodeling of splenic architecture by cytomegalovirus. PLoS Pathog. 2:e16. 